\title{
Synaptic Properties of Serotonergic Growth Cones in Developing Rat Brain
}

\author{
N. Ivgy-May, ${ }^{1}$ H. Tamir, ${ }^{1,2}$ and M. D. Gershon' \\ 'Department of Anatomy and Cell Biology, Columbia University College of Physicians and Surgeons, and ${ }^{2}$ Division of \\ Neuroscience, New York State Psychiatric Institute, New York, New York 10032
}

In order to gain insight into the events that take place when serotonergic growth cones are remodeled into synapses, we tested the hypothesis that neurotransmitter-related properties of presynaptic terminals are already present in these growth cones before synaptogenesis begins. The ontogeny of markers for the specific reuptake of 5-HT and for 5-HTstoring synaptic vesicles was studied in isolated growth cone (IGC) fractions from developing rat brain. High-affinity ${ }^{3} \mathrm{H}$-imipramine binding (a marker for the plasma membrane 5-HT transporter) was significantly enriched in IGC fractions prepared before the beginning of cortical synaptogenesis [embryonic day 15 (E15) and E20]. Radioautography with ${ }^{3} \mathrm{H}$-imipramine or ${ }^{3} \mathrm{H}$-paroxetine (another marker for the transporter) confirmed that the 5-HT transporter is present in the cerebral cortex when it contains serotonergic growth cones, but not serotonergic synapses. Specific uptake of ${ }^{3} \mathrm{H}-5-\mathrm{HT}$ was found in IGC fractions as early as E15; this uptake was inhibited by fluoxetine. Electron microscopic radioautography demonstrated directly that growth cones were the structures in IGC fractions that took up ${ }^{3} \mathrm{H}-5-\mathrm{HT}$. The synaptic vesicle protein synaptophysin and a $45 \mathrm{kDa}$ protein found specifically in serotonergic synaptic vesicles, serotoninbinding protein (SBP), were each enriched in IGC fractions from E15 to postnatal day 5; SBP immunoreactivity increased $\sim 10$-fold between E15 and E20. Endogenous 5-HT was detected in IGC fractions at E15 and increased in amount as development proceeded. The ratio of 5-HT to 5-hydroxyindole acetic acid suggested that 5-HT within growth cones is protected from catabolism by monoamine oxidase. Reserpineinduced depletion of 5-HT, a marker for the vesicular carrier of 5-HT, was apparent in IGC fractions at E20, but not at E15. These data suggest that properties that characterize the presynaptic components of mature serotonergic synapses develop in growth cones before synapses are formed. The early development of these properties may permit neurotransmission to be established rapidly during synaptogenesis or, alternatively, enable 5-HT to play a role in ontogeny.

IKey words: growth cones, growth and development, rat brain, 5-HT uptake, synaptic vesicles, 5-HT, GAP43, serotonin-binding protein, synaptophysin]

\footnotetext{
Received Mar. 5, 1993; revised July 23, 1993; accepted Aug. 26, 1993.

We thank Ms. Linda Friedman and Diane Sherman for their contribution to studies involving radioautography, and Dr. Maarten Reith for his generous contribution of norzimelidine. This work was supported by NIH Grants NS 12969 , NS 15547, and NIMH 37575.

Correspondence should be addressed to Dr. Michael D. Gershon, Department of Anatomy and Cell Biology, Columbia University, College of Physicians and Surgeons, 630 West 168th Street, New York, NY 10032.

Copyright (C) 1994 Society for Neuroscience $0270-6474 / 94 / 141011-19 \$ 05.00 / 0$
}

The functional properties of the vertebrate nervous system are critically dependent on the connections between neurons that are established during development. Axonal growth cones are the structures that are responsible for enabling axons to find their targets. In order to do so, growth cones must exhibit motility, have a guidance mechanism, and recognize target structures (Landis, 1983; Lockerbie, 1987; Bray and Hollenbeck, 1988; Devoto, 1990). Following synaptogenesis, properties associated with neurotransmission become critical. In order to function synaptically, monoaminergic axon terminals must contain synaptic vesicles, which enable the neurotransmitter to be stored, protected from catabolism by monoamine oxidase (MAO), and secreted. The terminals must also exhibit a reuptake mechanism to inactivate released transmitter, which is associated with the presence of a specific transporter molecule in the plasma membrane (Blakely et al., 1991; Hoffman et al., 1991). After contact with the prospective postsynaptic structure has been made, therefore, growth cones must be either replaced or remodeled to give rise to the presynaptic components of synapses. A major difference between these two possibilities is that a replacement hypothesis predicts a relative absence of synaptic mechanisms in growth cones, while the remodeling hypothesis predicts their presence. Replacement and remodeling are not necessarily mutually exclusive. Synaptogenesis might involve adding some new structures to axon terminals, while others are retained. Previous studies have demonstrated that growth cones may contain neurotransmitters and their biosynthetic enzymes (McLaughlin et al., 1975; Gotow and Sotelo, 1987; Westenbroek et al., 1988). Release of transmitters prior to the development of discernible synaptic contacts has also been observed (Hume et al., 1983; Young and Poo, 1983; Sun and Poo, 1987). What has not yet been established is whether or not the plasma membrane of growth cones is like that of mature presynaptic nerve terminals or whether growth cones contain synaptic vesicles. In order to study the degree to which growth cones share the neurotransmitter-related properties of presynaptic axon terminals, we analyzed the ontogeny of markers for the specific reuptake of 5-HT and for 5-HT-storing synaptic vesicles in isolated growth cone (IGC) fractions from developing rat brain. Serotonergic neurons were selected for this investigation, because although they are among the earliest neurons to develop in the mammalian brain, they do not form synapses until relatively late (Lauder and Bloom, 1974; Lauder et al., 1982; Lidov and Molliver, 1982a,b; Wallace and Lauder, 1983; Fujimiya et al., 1986). The delay in serotonergic synaptogenesis provides a window of opportunity during which the growth cones of serotonergic neurons can be investigated in the absence of synapses.

The precocious development of serotonergic neurons has led 
to proposals that 5-HT plays a role in the developmental process itself (Lauder, 1991). 5-HT has been demonstrated to be able to act as a growth/differentiation factor (Mattson, 1988; Hamon et al., 1989; Lipton and Kater, 1989; Lauder, 1991). Whether or not 5-HT functions in the development of the nervous system, the presence of 5-HT in the fetal brain before synaptogenesis takes place is compatible with the idea that 5-HT is located in growth cones. If so, then growth cones might be expected to share properties of presynaptic terminals. Synaptic vesicles in growth cones, for example, could accumulate 5-HT and thus protect the amine from catabolism by MAO, which is present in the fetal rat brain (Levitt et al., 1985; Liu et al., 1987). Storage in synaptic vesicles and a reuptake mechanism might also enable 5-HT to play a role in developmental signaling. Finally, the occurrence of transmitter-related properties in growth cones would speed the process by which growth cones are converted to synapses. Extensive synthesis of new protein would not be required if critical elements of the transmitter apparatus were preassembled prior to the initiation of neurotransmission.

Previous studies of the development of 5-HT-related markers have concentrated on whole-brain homogenates (Loizou, 1972; Loizou and Salt, 1970; Hamon and Bourgoin, 1982; Liu et al., 1987; Herregodts et al., 1990) or synaptosomes (Tissari, 1975). None have been focused on the extent to which serotonergic mechanisms are present in growth cones. We have studied the presence of the plasma membrane transporter, which is responsible for the uptake of 5-HT, and 5-HT-storing synaptic vesicles in isolated growth cone fractions as a function of age. Markers for the 5-HT transporter included the specific binding of ${ }^{3} \mathrm{H}$-imipramine (Marcusson et al., 1986, 1989; Graham et al., 1989) and ${ }^{3} \mathrm{H}$-paroxetine (Habert et al., 1985; DeSouza and Kuyatt, 1987; Hrdina et al., 1990), as well as the ability to take up ${ }^{3} \mathrm{H}-5-\mathrm{HT}$. Synaptic vesicle markers included synaptophysin, a protein found in the membrane of nearly all synaptic vesicles (Jahn et al., 1985; Wiedenmann and Franke, 1985; Navone et al., 1986; Floor and Feist, 1989; Sudhof and Jahn, 1991) and a form $(\sim 45 \mathrm{kDa})$ of serotonin-binding protein (SBP), which is found only in the synaptic vesicles of serotonergic neurons and the secretory vesicles of other 5-HT-storing cells that are derived from neuroectoderm (Jonakait et al., 1979; Tamir and Gershon, 1979; Gershon et al., 1983; Gershon and Tamir, 1984, 1985; Barasch et al., 1987; Kirchgessner ct al., 1988; Tamir ct al., 1990). Finally, we investigated, as a function of age, the ability of reserpine, which blocks the transport of monoamines into synaptic vesicles (Carlsson, 1965; Giachetti et al., 1974; Shore and Giachetti, 1978; Maron et al., 1979; Angelides, 1980), to deplete 5-HT. Our data are compatible with the idea that components of the transmitter machinery are present in growth cones prior to synaptogenesis.

\section{Materials and Methods}

Animals. Timed-pregnant Sprague-Dawley female rats were used. The gestational age of fetal rats was counted from the day on which a vaginal plug was found (E0). Postnatal animals were kept with their mothers and were weaned at postnatal day 21 (P21). Pregnant dams and postnatal rats were anesthetized with methoxyflurane (Pitman-Moore Inc., Washington Crossing, $\mathrm{NJ}$ ) and killed by decapitation.

Subfractionation of fetal and neonatal rat brains. Isolated growth cone (IGC) fractions were prepared by the procedure. of Pfenninger et al. (1983). Briefly, brains from fetal or neonatal animals were gently homogenized at $4^{\circ} \mathrm{C}$. The homogenates were centrifuged at $1660 \times g_{\max }$ (for $15 \mathrm{~min}$ ) to obtain a low-speed supernatant (LSS). The LSS was layered onto a discontinuous sucrose gradient and centrifuged at 242,000 $\times g_{\max }$ (for $40 \mathrm{~min}$ ). The band at the load $/ 0.75 \mathrm{~m}$ sucrose interface (the A fraction) was collected, diluted, and centrifuged at $39,000 \times g_{\max }$. This pellet was then resuspended in a minimal volume of the buffer used for binding assays $(120 \mathrm{~mm} \mathrm{NaCl}, 5 \mathrm{~mm} \mathrm{KCl}$, and $50 \mathrm{~mm}$ Tris $\mathrm{pH}$ 7.4) containing aprotinin (Sigma Chemical Co., St. Louis, MO), and was kept frozen at $-80^{\circ} \mathrm{C}$ until assayed. The IGC fraction collected from the load $/ 0.75 \mathrm{M}$ interface is contaminated by supernatant material. The IGC fraction was therefore diluted to a final concentration of $0.25 \mathrm{M}$ sucrose (containing $1 \mathrm{~mm} \mathrm{MgCl}$ and $1 \mathrm{~mm} N$-tris[hydroxymethyl]methyl2 -aminoethane-sulfonic acid, $\mathrm{pH}$ 7.3) and centrifuged $\left(116,000 \times g_{\max }\right.$ for $90 \mathrm{~min}$ ) through a layer of $0.45 \mathrm{M}$ sucrose. IGCs were collected above a cushion of Maxidens oil (Sigma Chemical Co.). ${ }^{3} \mathrm{H}-5-\mathrm{HT}$ was used to evaluate the degree to which IGC fractions were contaminated by soluble material. ${ }^{3} \mathrm{H}-5-\mathrm{HT}$ was added to the diluted IGC fraction immediately before it was subjected to centrifugation through $0.45 \mathrm{M} \mathrm{su}$ crose. The amount of radioactivity present in the IGC fraction collected over Maxidens oil was then determined. Since the growth cones were exposed to ${ }^{3} \mathrm{H}-5-\mathrm{HT}$ in a medium that did not contain $\mathrm{Na}^{+}$, the temperature was $4^{\circ} \mathrm{C}$, and membranes are impermeable to 5-HT, accumulation of ${ }^{3} \mathrm{H}-5$-HT within growth cones should be minimal. ${ }^{3} \mathrm{H}-$ 5-HT appearing in the material at the $0.45 \mathrm{~m}$ sucrose/Maxidens oil interface, therefore, provides an estimate of how much soluble material is trapped in the final IGC fraction. In the same experiments, endogenous 5 - $\mathrm{HT}$ (in addition to added ${ }^{3} \mathrm{H}-5-\mathrm{HT}$ ) was also measured. These measurements indicated that very little of the endogenous 5-HT found in IGC fractions could have been derived from supernatant contamination. In a typical experiment (E20), the concentration of endogenous $5-\mathrm{HT}$ in the supernatant fraction was $11.8 \pm 2.5 \mathrm{pmol} / \mathrm{ml}$. On the basis of this value, and the volume of supernatant present in the fraction collected over Maxidens oil (estimated from the amount of ${ }^{3} \mathrm{H}-5-\mathrm{HT}$ recovered in this fraction), the supernatant was calculated to contribute $0.4 \mathrm{pmol}$ of 5 -HT to the IGC fraction. The purified IGC fractions, however, were observed to contain $10.4 \pm 2.0$ pmol of 5 -HT per fraction. Supernatant contamination, therefore, is responsible for only about $4 \%$ of the $5-\mathrm{HT}$ experimentally found in the purified IGC fraction.

Synaptosomes were prepared according to the method of Cohen et al. (1977) and kept at $-80^{\circ} \mathrm{C}$ until used.

Preparation of fractions for electron microscopy. The fractions were processed for electron microscopy (EM) as described previously (Pfenninger et al., 1983). Briefly, aliquots of the various fractions were mixed with gradually increasing amounts of $1.5 \%$ glutaraldehyde in $0.2 \mathrm{M}$ phosphate buffer (pH 7.3) to which $120 \mathrm{~mm}$ glucose and $0.4 \mathrm{M} \mathrm{CaCl}_{2}$ were added. The fixed material was pelleted, washed with arsenate buffer, stained en bloc with magnesium uranyl acetate, dehydrated, and embedded in Epon 812. Thin sections prepared from these pellets were doubly stained with uranyl acetate and lead citrate and examined with a JEOLCO $100 \mathrm{~S}$ electron microscope.

Galactosyltransferase assay. In order to evaluate the relative contamination of the IGC fraction by membranes derived from the Golgi apparatus, activity in the IGC fraction of a Golgi marker, galactosyltransferase, was assayed and compared to that of the LSS fraction. Activity of the enzyme in the fractions was determined as previously described (Bretz and Staubli, 1977). Several concentrations of membranes were tested to make certain that the activity was measured within a linear range of enzyme activity. Blank values were determined in the absence of membranes.

Phospholipids. In order to determine the phospholipid content of fractions, lipids were extracted with chloroform-methanol $(2: 1)$ and the lower phase was used for measurement of phosphate. The protein concentration in the fractions was determined according to the method of Lowry et al. (1951). Proteins in the fractions were separated and their glial fibrillary acidic protein (GFAP) immunoreactivity was analyzed on nitrocellulose blots.

Assays of ${ }^{3} \mathrm{H}$-imipramine binding by rapid filtration. ${ }^{3} \mathrm{H}$-imipramine binding to brain fractions was measured by a modification of the method of Raisman et al. (1979). In order to construct saturation isotherms, the LSS was collected and centrifuged again $\left(65,000 \times g_{\max }\right.$ for $\left.1 \mathrm{hr}\right)$, and the pellet was resuspended in a minimal volume of the incubation buffer and diluted to a concentration of $\sim 1.0 \mathrm{mg}$ protein $/ \mathrm{ml}$. Twelve concentrations of ${ }^{3} \mathrm{H}$-imipramine ( $0.3-10 \mathrm{~nm}$ ) were used. Nonspecific binding was estimated by using norzimelidine as a displacing agent (Marcusson et al., 1985). Specific binding was defined as total binding minus that found in the presence of $1 \mu \mathrm{M}$ norzimelidine. The assay was initiated by adding $100 \mu \mathrm{g}$ of membranes to each of the solutions containing ${ }^{3} \mathrm{H}-$ imipramine (final volume, $0.3 \mathrm{ml} /$ tube). Membranes were incubated for 
$60 \mathrm{~min}$ at $0-2^{\circ} \mathrm{C}$. The reaction was terminated by adding $3 \mathrm{ml}$ of iced buffer and filtering the reaction mixture through Whatman GF/B filters that had been presoaked in incubation buffer containing $0.1 \%(\mathrm{v} / \mathrm{v})$ polyethylenimine to diminish nonspecific binding to the filters. A 24channel cell harvester (Brandel, Gaithersburg, MD) was used for filtration and the filters were washed twice with $3 \mathrm{ml}$ of iced buffer. Radioactivity trapped by the filters was determined by liquid scintillation spectroscopy. For experiments in which the relative binding of ${ }^{3} \mathrm{H}$ imipramine in different subcellular fractions was measured, a single concentration of ${ }^{3} \mathrm{H}$-imipramine, $6 \mathrm{nM}\left(3 \times K_{d}\right)$, was employed.

Radioautographic localization of ${ }^{3} \mathrm{H}$-imipramine and ${ }^{3} \mathrm{H}$-paroxetine. The binding of ${ }^{3} \mathrm{H}$-imipramine to sections mounted on glass slides was assessed radioautographically (Grabowsky et al., 1983). Briefly, fetal rats (E20) were perfused intracardially with iced $0.1 \%$ formaldehyde solution in isotonic phosphate-buffered saline (PBS). Fetal brains were rapidly dissected and frozen in embedding medium (OCT, Lipshaw) cooled by liquid $\mathrm{N}_{2}$. Sections $12 \mu \mathrm{m}$ in thickness were cut from several brain regions at $-20^{\circ} \mathrm{C}$ using a cryostat microtome (Hacker Instruments Inc.). The sections were thaw-mounted onto microscope slides coated with chromium alum/gelatin and preincubated with $50 \mathrm{~mm}$ Tris- $\mathrm{HCl}$ $\left(\mathrm{pH} 7.4\right.$ at $25^{\circ} \mathrm{C}$ ) for $15 \mathrm{~min}$. Following this treatment, the tissues were exposed to 4-10 $\mathrm{nM}^{3} \mathrm{H}$-imipramine in $50 \mathrm{~mm}$ Tris- $\mathrm{HCl}$ buffer containing $120 \mathrm{~mm} \mathrm{NaCl}$ and $5 \mathrm{mM} \mathrm{KCl}$ for $60 \mathrm{~min}$ at $4^{\circ} \mathrm{C}$. Nonspecific binding was determined in adjacent sections, incubated identically as above, except that the incubating solution also contained $1.0 \mu \mathrm{M}$ norzimelidine. Dependence of ${ }^{3} \mathrm{H}$-imipramine binding on $\mathrm{Na}^{+}$was investigated by omitting $\mathrm{NaCl}$ from the incubation buffer to which additional adjacent sections were exposed. Following incubation, slides were washed with a quick dip, followed by rinsing with iced buffer solution for 10 and then $20 \mathrm{~min}$. Salts were removed by a quick dip in iced distilled water and tissues were rapidly dried in a stream of dry filtered air. Labeled sections were exposed to ${ }^{3} \mathrm{H}$-sensitive film (Ultrofilm, LKB) (Palacios et al., 1981) for 2-3 weeks at $4^{\circ} \mathrm{C}$. Binding of ${ }^{3} \mathrm{H}$-paroxetine to sections (De Souza et al., 1987) was assayed by a method similar to that used for the evaluation of the binding of ${ }^{3} \mathrm{H}$-imipramine except that fluoxetine $(30 \mu \mathrm{M})$ was used to evaluate nonspecific binding. Slides were incubated with $1.0 \mathrm{nM}{ }^{3} \mathrm{H}$-paroxetine (specific activity, $26.5 \mathrm{Ci} / \mathrm{mmol}$ ) for $60 \mathrm{~min}$ at room temperature. Labeled sections were exposed to ${ }^{3} \mathrm{H}$-sensitive film for 12-16 weeks at $4^{\circ} \mathrm{C}$. Radioautograms were then analyzed quantitatively by computer-assisted video microdensitometry (Imaging Research Corp., St. Catherines, Ontario, Canada).

Uptake of ${ }^{3} \mathrm{H}-5-\mathrm{HT}$ by IGC fractions. For measurement of ${ }^{3} \mathrm{H}-5-\mathrm{HT}$ uptake, IGC fractions were prepared as described above; however, since intact growth cones were needed, the last centrifugation step was omitted. Instead, the A band was collected and dialyzed against a large volume of Krebs solution saturated with a mixture of $95 \% \mathrm{O}_{2}$ and $5 \%$ $\mathrm{CO}_{2}$ for $1.5 \mathrm{hr}$ at $4^{\circ} \mathrm{C}$. The dialyzed IGC fraction $(450 \mu \mathrm{l}$, containing $\sim 1 \mathrm{mg}$ protein) was added to a tube that contained ${ }^{3} \mathrm{H}-5-\mathrm{HT}(0.5 \mu \mathrm{M}$ final concentration). The tubes were incubated in a shaker bath for 5$10 \mathrm{~min}$ at $37^{\circ} \mathrm{C}$ in an atmosphere of $95 \% \mathrm{O}_{2}$ and $5 \% \mathrm{CO}_{2}$. Uptake of ${ }^{3} \mathrm{H}-5-\mathrm{HT}$ in the presence of fluoxetine $(25 \mu \mathrm{M})$ was used to estimate nonspecific uptake. As a second control, nonspecific uptake was also measured by incubating the IGC fraction with ${ }^{3} \mathrm{H}-5-\mathrm{HT}$ at $4^{\circ} \mathrm{C}$. Reactions were terminated by adding $3 \mathrm{ml}$ of iced buffer to each tube and immediately thereafter filtering the contents through Whatman GF/B glass fiber filters. Filters were washed twice with $3 \mathrm{ml}$ of iced buffer and counted by liquid scintillation spectroscopy.

$E M$ radioautography of ${ }^{3} \mathrm{H}-5-\mathrm{HT}$. The A fraction at $\mathrm{P} 3$ was incubated with ${ }^{3} \mathrm{H}-5-\mathrm{HT}$ in the presence or absence of fluoxetine as described above. At the end of the incubation period, the fractions were cooled on ice in order to stop the uptake process, and were then mixed gradually with a 10 -fold greater volume (to dilute the free ${ }^{3} \mathrm{H}-5$ - $\mathrm{HT}$ ) of $1.5 \%$ glutaraldehyde in $0.2 \mathrm{M}$ phosphate buffer (pH 7.3) containing $120 \mathrm{~mm}$ glucose and $0.4 \mathrm{M} \mathrm{CaCl}_{2}$. Further processing was as described above for routine electron microscopy. Pale gold-colored sections were cut and prepared for radioautography with Ilford L-4 emulsion as described previously (Erde et al., 1985). After 3 weeks of exposure under $\mathrm{CO}_{2}$, the slides were developed with Kodak Microdol-X $(3 \mathrm{~min})$ and fixed.

Grain distribution on electron microscopic radioautographs was analyzed by the method of Williams (1969). Essentially, probability circles, equal in diameter $(240 \mathrm{~nm})$ to 1.5 times the half-distance (the distance from a radioactive line within which $50 \%$ of developed silver grains will lie; Salpeter et al., 1969), were placed around each silver grain and potential radioactive sources within the circles were scored. A regular grid of similar circles placed over the fraction and scored similarly served to evaluate the distribution that would be expected if the grains were randomly distributed in the fraction. Relative specific activity of the components was defined as the percentage of grains associated with the component, divided by the percentage of random circles (the effective area) associated with the same component. Grain distribution was compared with the circle distrihution (expected distribution) by means of a $\chi^{2}$ analysis. Components were defined as labeled if significantly more grains fell over them than would have been expected for a random distribution $(p<0.001)$. After an initial analysis revealed that the distribution of silver grains was not random, grains associated with junctional items (covering two or more components) were reapportioned to the individual components. In doing this, it was assumed that the relative specific activity of the individual components of junctional items was equal to that of the same components occurring as single items. The volumes of the individual components were estimated by point count planimetry (Elias et al., 1971) and reapportionment was done taking into account both their relative specific activities and their volumes.

Measurements of endogenous 5-HT. Pregnant rats were injected intraperitoneally with reserpine $(5 \mathrm{mg} / \mathrm{kg}$; CIBA Pharmaceutical Co., Basel, Switzerland) or saline (controls). Neonatal rats were injected similarly, except that injections were administered subcutaneously. On the day after the injections, brains were removed, homogenized, and fractionated as described above. The fractions obtained were frozen at $-80^{\circ} \mathrm{C}$ and stored for no more than 1-2 d prior to assay of 5-HT and 5-hydroxyindoleacetic acid (5-IIIAA) levels. Fractions were homogenizzed in a buffer ( $\mathrm{pH} 3.9$ ) containing $0.1 \mathrm{M}$ trichloroacetic acid (TCA), $0.1 \%$ cysteine (added as an antioxidant), $0.01 \mathrm{M}$ sodium acetate, and $18 \%$ methanol (TCA/cysteine buffer). The homogenate was centrifuged for $5 \mathrm{~min}$ at $15,000 \times \mathrm{g}$. The clear supernatant was then collected, and aliquots were injected directly into an HPLC system (LC 50, Waters Assoc., Milford, MA). The HPLC system consisted of a "Guard Column" (Whatman Inc., Clifton, NJ), a Waters C-18 $\mu$ Bondapak reversephase column $(4 \mathrm{~mm} \times 30 \mathrm{~cm})$, and an LC- $4 \mathrm{~A}$ amperometric detector, coupled to a TL-5 glassy carbon electrode (Bioanalytical Systems, West Lafayette, IN). TCA/cysteine buffer was used as a mobile phase at a flow rate of $1 \mathrm{ml} / \mathrm{min}$. The electrochemical detector was set at $0.7 \mathrm{~V}$. A Waters data module (M730) was used to estimate amounts of compounds present in solutions.

Gel electrophoresis and immunoblotting. Proteins were separated by SDS-PAGE using a separating gel containing $8.5 \%$ acrylamide (Laemmli, 1970). Following separation by electrophoresis, proteins were electroblotted onto nitrocellulose (Towbin et al., 1979) and incubated for $1 \mathrm{hr}$ at room temperature with a blocking solution containing $2.6 \mathrm{~mm}$ $\mathrm{KCl}, 136 \mathrm{~mm} \mathrm{NaCl}, 10 \mathrm{~mm}$ potassium phosphate buffer (PBS; pH 7.3), $0.05 \%$ Tween- 20 , and $5 \%$ nonfat dry milk solids (Carnation). The nitrocellulose blots were then exposed to rabbit antibodies to synaptophysin (serum G96, diluted 1:500; kindly provided by Dr. R. Jahn, Martinsreid, Germany) (Jahn et al., 1985), rabbit antibodies to glial fibrillary acidic protein (GFAP; diluted 1:500; donated by Dr. G. Nilaver, University of Oregon), rabbit antibodies to $45 \mathrm{kDa}$ SBP (TM5, diluted 1:2000) in blocking solution, or murine monoclonal antibodies to GAP43 (diluted 1:5000; donated by Dr. David Schreyer of Stanford University, Palo Alto, CA) (Goslin et al., 1988, 1990). Blots remained in contact with primary antibodies overnight. Immunoreactivity was detected with affinity-purified biotinylated goat anti-rabbit secondary antibodies (diluted 1:400; $2 \mathrm{hr}$; Kirkegaard and Perry) and avidin coupled to alkaline phosphatase (diluted 1:400; $1 \mathrm{hr}$; Vector Laboratories). Alkaline phosphatase-labeled probes were visualized by demonstrating the activity of the enzyme with a commercial reagent (Vector Laboratories, Kit III) that produces a blue reaction product. Alternatively, ${ }^{125}$ labeled protein A ( $4 \times 10^{5} \mathrm{cpm} / \mathrm{ml}$; in blocking solution; ICN Corp.) was used instead of secondary antibodies and visualized by radioautography. ${ }^{125}$ I-labeled protein A was also utilized to obtain quantitative estimaies of the relative amounts of SBP immunoreactivity in various fractions. In this case, the radioactive bands located by radioautography were cut out of the nitrocellulose supports and counted. A linear relationship was found to exist between the protein content of fractions (or a partially purified SBP preparation) applied to gels and the radioactivity bound to the nitrocellulose supports (Fig. 1). In control experiments, primary antibodies were omitted or blots were incubated with preimmune serum.

In order to obtain a quantitative estimate of the amounts of synaptophysin immunoreactivity present in various cell fractions, a dot-immunobinding assay was used (Jahn et al., 1984). Fractions were diluted 

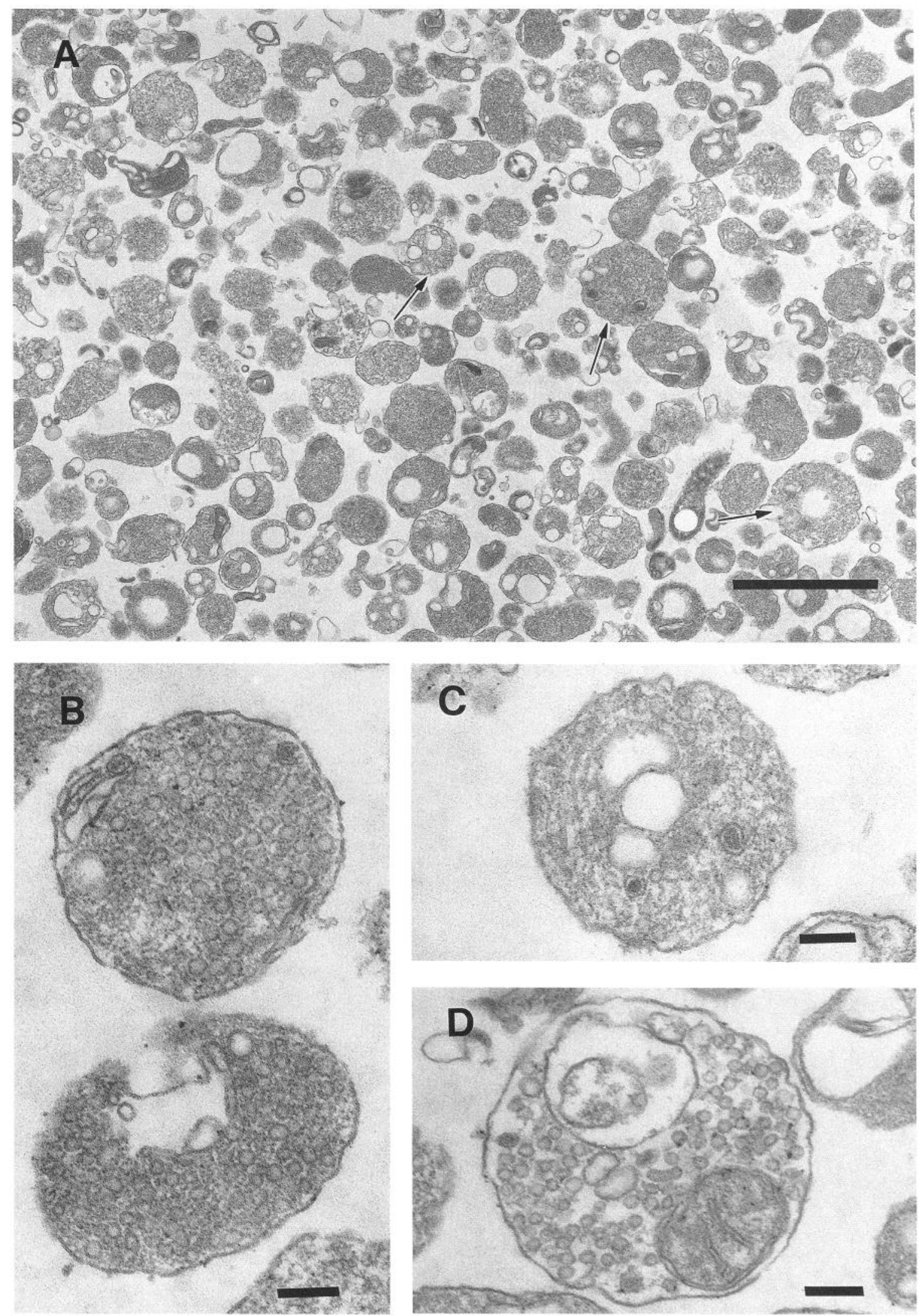

Figure 1. An electron micrograph of an IGC fraction prepared from postnatal rat brain (P9). A, The fraction consists primarily of membranebounded cellular fragments (arrows) of variable size $(0.3-1.5 \mu \mathrm{m})$. There are no rough microsomes. $B-D$, At higher magnification, the cellular fragments can be seen to contain variously shaped vesicles $(B, D)$, vacuoles $(C, D)$, and mitochondria $(D)$. Some $(C)$ contain dense-cored vesicles. These fragments are the structures identified as IGC. Note the absence of internal ribosomes and the paucity of bundles of microtubules and microfilaments. The single large vacuolar structure in $D$ is probably an invagination of the plasma membrane (Lockerbie et al., 1991). Scale bars: $A, 2 \mu \mathrm{m} ; B-D, 0.5 \mu \mathrm{m}$. 
in sample buffer $\left(120 \mathrm{~mm} \mathrm{KCl}, 20.0 \mathrm{~mm} \mathrm{NaCl}, 2.0 \mathrm{~mm} \mathrm{NaHCO}_{3}, 2.0\right.$ $\mathrm{mM} \mathrm{MgCl}_{2}, 5.0 \mathrm{~mm}$ HEPES pH 7.4, and $0.7 \%$ Triton X-100), spotted onto a nitrocellulose support, rinsed with water, air dried, and fixed for $15 \mathrm{~min}$ in a solution containing $10 \%$ acetic acid and $25 \%$ isopropanol. Following fixation, the nitrocellulose supports were washed and processed as described above for immunoblots. Antibodies to synaptophysin (diluted 1:500 in blocking solution containing $0.1 \%$ Triton $X-100$ ) were applied. ${ }^{125}$ I-protein $\mathrm{A}\left(\sim 4 \times 10^{5} \mathrm{cpm} / \mathrm{ml}\right.$, diluted in blocking solution containing $0.1 \%$ Triton X-100) was used to detect bound antibody. Assays were carried out at two or three concentrations of antigen to verify that radioactivity increased as a linear function of the protein concentration.

Materials. ${ }^{3} \mathrm{H}$-imipramine $(48.6 \mathrm{Ci} / \mathrm{mmol}),{ }^{3} \mathrm{H}$-paroxetine $(26.5 \mathrm{Ci} /$ $\mathrm{mmol})$, and ${ }^{3} \mathrm{H}-5-\mathrm{HT}(28-30 \mathrm{Ci} / \mathrm{mmol})$ were each obtained from New England Nuclear Corp. (Buston, MA). Unlabeled norzimelidine was kindly provided by Dr. Maarten E. A. Reith (Nathan S. Kline Institute for Psychiatric Research, New York, NY). Fluoxetine was obtained from Eli Lilly and Co. (Indianapolis, IN), and desipramine (DMI), from Sigma Chemical Co. (St. Louis, MO).

\section{Results}

\section{Characterization of the IGC fractions}

The morphology of the IGC fractions suggests that they are enriched in growth cones. Since there is no accepted biochemical marker for growth cones, an essential criterion used in characterizing IGC fractions has been their ultrastructure. It is also important to rule out, as much as possible, contamination of IGC fractions by fragments derived from structures other than growth cones. The morphological properties of rat IGC have previously been defined on the basis of observations made on material prepared from prenatal brains (Pfenninger et al., 1983); therefore, IGC fractions obtained from the brains of postnatal rats ( $\mathrm{P} 3$ and $\mathrm{P} 9$ ) were examined by $\mathrm{EM}$ and their morphology was compared to that of the prenatal material (Fig. 1). The morphology of postnatal IGC fractions was found to be virtually identical to that described by Pfenninger et al. (1983) for a similar fraction obtained from fetal brain. Specifically, membrane-bounded cellular fragments of variable size $(0.3-1.5 \mu \mathrm{m})$ were abundant. These fragments contained mitochondria, microfilaments, and irregularly shaped vesicles and vacuoles. As previously noted (Lockerbie, 1990), internal membranes, which have been interpreted to be elements of smooth endoplasmic reticulum, were numerous. The cellular fragments lacked internal ribosomes (suggesting that they are derived from axons and not dendrites or glia) or assembled arrays of microtubules (suggesting that they are derived from terminals and not axonal shafts). Importantly, no evidence of myelin contamination was visible in electron micrographs of IGC fractions at P3 and almost no myelin was seen at $\mathrm{P9}$.

The IGC fraction contains little GFAP: mature synaptosomes do not co-sediment with growth cones. The suggestion that the cellular fragments were not derived from glia was supported by immunoblots probed with antibodies to GFAP (data not illustrated). Almost no GFAP immunoreactivity was detected in the $\mathrm{IGC}$ fraction, but was present in small amounts in the LSS from which the IGC fraction was obtained. Although the accumulation of small vesicles in a few of the cell fragments caused them to resemble synaptosomes, adherent postsynaptic membranes, which characterize synaptosomes, were not observed; nevertheless, experiments were carried out to determine where mature synaptosomes would have sedimented if they had been present in the homogenates of developing brain. Synaptosomes were prepared from adult brain and labeled by incubation for 10 min with ${ }^{3} \mathrm{H}-5-\mathrm{HT}(0.5 \mu \mathrm{M})$. The ${ }^{3} \mathrm{H}-5-\mathrm{HT}$-labeled synaptosomes were mixed with the LSS obtained from the brain of

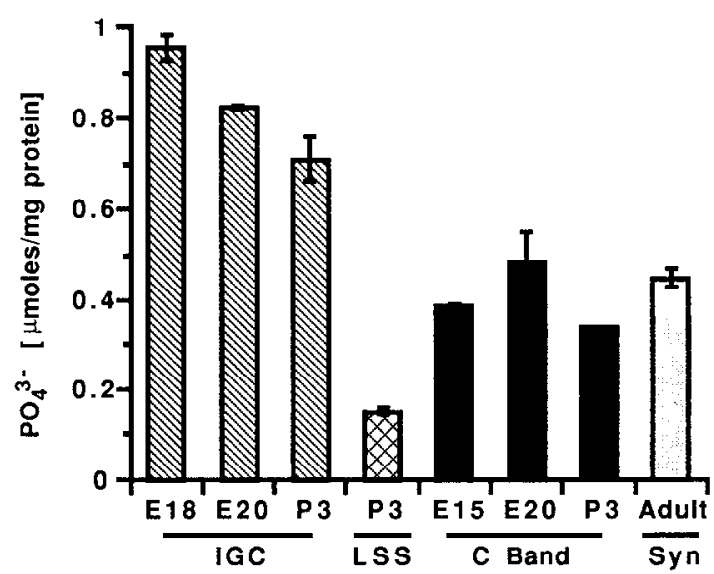

Figure 2. A histogram showing the phospholipid : protein ratio of different brain fractions at $P 3$. Note that the ratio is higher in the IGC fraction than in the LSS fraction, a heavier ("C") fraction, or in synaptosomes collected from adult rat brains. Similar results were obtained at E18 and E20. Values are the means \pm SE of three independent measurements, each carried out in triplicate.

a rat at E20 and the IGC fraction was prepared in the usual manner. ${ }^{3} \mathrm{H}-5-\mathrm{HT}$, which leaked from the synaptosomes, was recovered in the supernatant $\left(\sim 36 \%\right.$ of the recovered ${ }^{3} \mathrm{H}-5-$ $\mathrm{HT}$ ), while most of the remaining ${ }^{3} \mathrm{H}-5-\mathrm{HT}(\sim 58 \%)$ sedimented in the "C" band, which is collected at the interface between 1.0 and $2.55 \mathrm{M}$ sucrose. Very little ${ }^{3} \mathrm{H}-5$-HT $(\sim 6 \%)$ was found in the remaining IGC and " $B$ " fractions. Mature synaptosomes would thus not be likely to sediment with growth cones in the IGC fractions, even if they were to be present in the developing material subjected to fractionation. Instead, mature synaptosomes would probably be found in the heavier and very heterogeneous " $\mathrm{C}$ " fraction.

The IGC fraction is enriched in membranes but myelin and Golgi contamination is minimal. An identifying feature of growth cones is their extensive system of internal membranes; therefore, the phospholipid content of the fractions was measured and used as a membrane marker (Fig. 2). The IGC fraction was found to contain significantly more phospholipid per unit of protein than did the LSS, the "C" fraction, or synaptosomes from adult brain. Since the phospholipid-to-protein ratio of myelin fragments would also be high, the potential contamination of the IGC fraction by myelin was assayed as a function of age (although almost no myelin was visible in electron micrographs as late as P9). Immunoblots were prepared and probed with antibodies to myelin basic protein (MBP). Little or no MBP immunoreactivity was detected in the IGC fractions between E1 5 and P3 (not illustrated); however, at P27 this fraction contained a great deal of MBP immunoreactivity. The high lipidto-protein ratio found in the IGC fraction on $\mathrm{P} 3$ and earlier therefore cannot be ascribed to myelin. The absence of MBP immunoreactivity also implies that the IGC fractions contain little or no membrane derived from oligodendrocytes. Another potential source of membranous material that might sediment like growth cones is the Colgi apparatus. A significant proportion of the membranous material visible in electron micrographs of the IGC fraction ( $\sim 19 \%$ of the volume of the fraction) could not be morphologically identified, because the particles either were cut tangentially or lacked sufficient ultrastructural detail; therefore, the extent of contamination by Golgi-derived membranes was estimated biochemically. Galactosyltransferase ac- 
Table 1. Distribution of galactosyltransferase in developing brain fractions

\begin{tabular}{|c|c|c|c|c|c|c|c|c|c|}
\hline \multirow{3}{*}{$\begin{array}{l}\text { Frac- } \\
\text { tion }\end{array}$} & \multicolumn{3}{|l|}{$\mathrm{E} 20$} & \multicolumn{3}{|l|}{$\mathrm{P} 3$} & \multicolumn{3}{|l|}{ P9 } \\
\hline & \multirow{2}{*}{$\begin{array}{l}\text { Protein } \\
(\% \text { Rec })\end{array}$} & \multicolumn{2}{|c|}{ GalTase activity } & \multirow{2}{*}{$\begin{array}{l}\text { Protein } \\
(\% \text { Rec })\end{array}$} & \multicolumn{2}{|c|}{ GalTase activity } & \multirow{2}{*}{$\begin{array}{l}\text { Protein } \\
(\% \text { Rec) }\end{array}$} & \multicolumn{2}{|c|}{ GalTase activity } \\
\hline & & $\% \operatorname{Rec}$ & RSA $^{a}$ & & $\% \operatorname{Rec}$ & RSA & & $\% \operatorname{Rec}$ & RSA \\
\hline$\overline{\mathrm{LSS}}$ & 100 & 100 & 1.00 & 100 & 100 & 1.00 & 100 & 100 & 1.00 \\
\hline IGC & 2.4 & 0.8 & $0.45 \pm 0.05$ & 2.3 & 1.4 & 0.59 & 4.9 & 2.0 & 0.40 \\
\hline B & 8.5 & 8.0 & $1.15 \pm 0.1$ & 8.9 & 24.2 & 2.23 & 12.0 & 11.8 & 0.98 \\
\hline $\mathrm{C}$ & 23.8 & 21.2 & $1.48 \pm 0.2$ & 20 & 34.1 & 1.33 & 34.9 & 33.3 & 0.95 \\
\hline Total & 34.6 & 30.0 & - & 31.3 & 59.7 & - & 51.8 & 47.1 & - \\
\hline
\end{tabular}

Data show relative specific activity (RSA) of galactosyltransferase (GalTase) in IGC, B, and C fractions. Protein and GalTase activity measured in each fraction are expressed as percentage of LSS (\% Rec);100\% of the enzyme activity and the protein applied to the gradient (i.e., LSS) was recovered when the material remaining in the gradient after the fractions were collected was also assaycd. RSA $=$ GalTase $\%$ rec/protein $\% \mathrm{rec}$.

${ }^{a}$ RSA values for E20 are an average \pm SE of five different experiments, whereas the other values in the table are derived from one experiment.

tivity was assayed (at E20, P3, and P9) and served as a Golgi marker (Table 1). No enrichment of galactosyltransferase activity in the IGC fraction was observed at any of these ages. In fact, the relative specific activity of galactosyltransferase was significantly lower in the IGC than in either the LSS or the two heavier subfractions (B and C). It is concluded that the IGC fraction is unlikely to contain mature synaptosomes, has a high phospholipid-to-protein ratio, is impoverished in Golgi-derived elements, and is predominantly composed of cellular fragments, the structure of which is consistent with a derivation of these fragments from axonal growth cones. The absence of ribosomes, GFAP, and MBP immunoreactivities supports the idea that the cellular fragments in this fraction (between E15 and P3) are derived from axons, rather than from astrocytes or oligodendrocytes.

\section{${ }^{3} \mathrm{H}$-imipramine binding sites in subcellular fractions of developing and adult brain are comparable}

${ }^{3} \mathrm{H}$-imipramine binding is a marker for the plasma membrane 5-HT transporter in adult animals (Marcusson et al., 1986, 1989; Graham et al., 1989); however, in order to use this parameter as such a marker in developing animals, it is necessary to show that the ${ }^{3} \mathrm{H}$-imipramine binding sites in the developing brain are comparable to those of adults. ${ }^{3} \mathrm{H}$-imipramine binding was therefore characterized in the developing brain. Initial experiments were carried out with synaptosomes isolated from adult rat brains and with the LSS fractions from fetal brains (E15 and E20) in order to determine optimal parameters for analysis of the binding of ${ }^{3} \mathrm{H}$-imipramine. ${ }^{3} \mathrm{H}$-imipramine binds only to neuronal membranes; therefore, the LSS fraction can be used, despite its heterogeneity, to characterize ${ }^{3} \mathrm{H}$-imipramine binding to membranes from the developing brain. When fractions were incubated with ${ }^{3} \mathrm{H}$-imipramine $(6.0 \mathrm{~nm})$ at $4^{\circ} \mathrm{C}$ for $1 \mathrm{hr}$, specific binding was found to increase linearly as a function of protein concentration in the range of $20-140 \mu \mathrm{g}$ of protein for synaptosomes and 60-210 $\mu \mathrm{g}$ protein for the LSS fractions. Specific binding of ${ }^{3} \mathrm{H}$-imipramine obtained under these conditions was approximately $43 \%$ of the total binding and represented $1-3 \%$ of the total cpm added to the incubation medium. All subsequent assays, therefore, were conducted at protein concentrations of $80-120 \mu \mathrm{g} /$ tube.

When binding of ${ }^{3} \mathrm{H}$-imipramine to membranes derived from developing and adult rat brains was measured as a function of the ${ }^{3} \mathrm{H}$-imipramine concentration, saturable, high-affinity, specific binding was found (Fig. 3). Computer-assisted nonlinear least-squares analysis (LUNDON-L) of the saturation isotherms indicated that the data were best described by a model that assumes a single population of ${ }^{3} \mathrm{H}$-imipramine binding sites; moreover, a linear Scatchard plot was obtained and the Hill coefficient (0.97) was close to unity. The $B_{\max }$ and $K_{d}$ values computed at different ages are summarized in Table 2. Note that specific high-affinity ${ }^{3} \mathrm{H}$-imipramine binding sites could already be detected at E15. At this time the $K_{d}$ for ${ }^{3} \mathrm{H}$-imipraminc binding was not significantly different from that determined for adult synaptosomes. The $K_{d}$, furthermore, was not found to change significantly during ontogeny. At E15, the $B_{\max }$ for ${ }^{3} \mathrm{H}$-imipramine binding was about $18 \%$ of that of adult synaptosomes. The $B_{\max }$ increased at later ages and by P15 was about $60 \%$ of that of the adult synaptosomal value. Since only a single high-affinity ${ }^{3} \mathrm{H}$-imipramine binding site was found with a $K_{d}$ that did not change significantly during ontogeny, it is concluded that ${ }^{3} \mathrm{H}$-imipramine binding sites in the developing brain are comparable to those in the brains of adults.

\section{${ }^{3} H$-imipramine binding sites are enriched in IGC fractions early in development}

The binding of ${ }^{3} \mathrm{H}$-imipramine ( $6 \mathrm{nM}$ ) was measured in LSS and IGC fractions derived from developing rat brain as a function of developmental age (Table 3 ). On E15, ${ }^{3} \mathrm{H}$-imipramine binding in the IGC fractions was enriched 3.7 -fold $(p<0.05)$ over that found in the LSS fractions from which the IGC fractions were derived. This enrichment persisted on E20 and was 2.4-fold greater in the IGC than in the LSS fractions $(p<0.05)$. After E20 the IGC fraction no longer exhibited significant enrichment in ${ }^{3} \mathrm{H}$-imipramine binding sites. In fact, the binding of ${ }^{3} \mathrm{H}$-imipramine in the IGC fraction declined sharply postnatally and by P27 was only $25 \%$ of that found on E20 ( $p<0.01)$. As a control, the binding of ${ }^{3} \mathrm{H}$-imipramine was assayed in the heavier " $\mathrm{C}$ " fractions, obtained from the same material from which the IGC, fractions were isolated, and in which mature synaptosomes would be found had they been present (Table 3). At none of the ages tested was ${ }^{3} \mathrm{H}$-imipramine binding significantly greater in the "C" band than in the LSS.

The developing rat cortex contains ${ }^{3} \mathrm{H}$-imipramine and ${ }^{3} H$-paroxetine binding sites, when serotonergic growth cones are present prior to synaptogenesis, at E20

Previous studies have established that serotonergic axons reach the cerebral cortex prior to, or on, E20; however, these axons do not form synapses at this time (Lidov and Molliver, 1982a). 


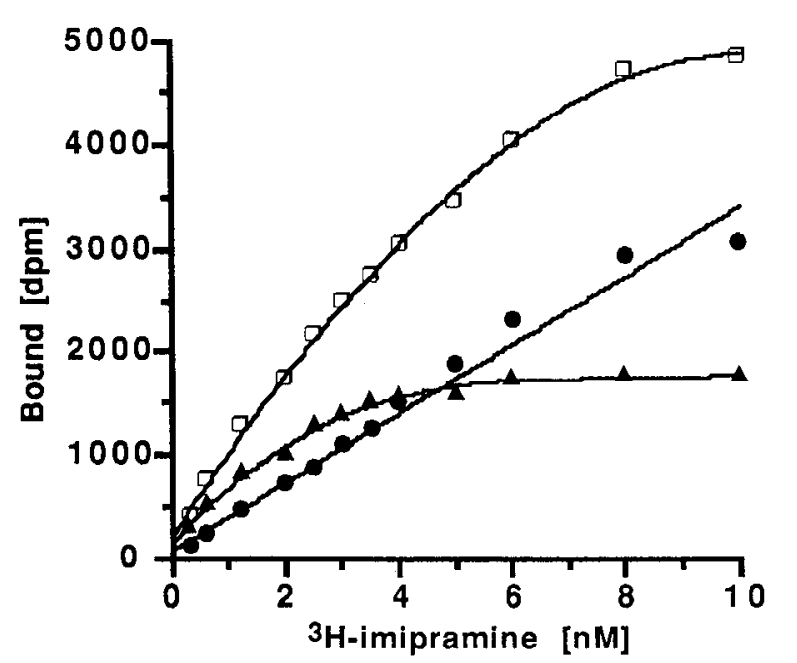

A

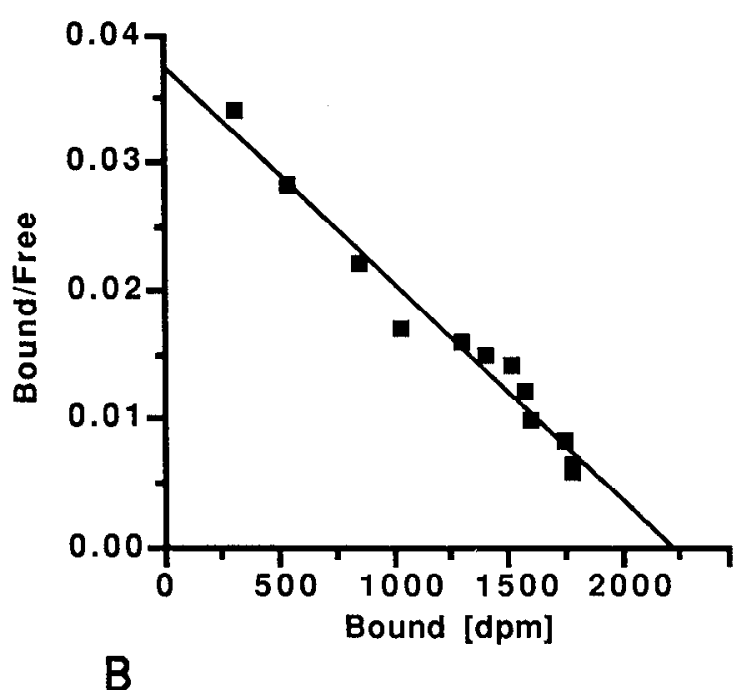

Figure 3. ${ }^{3} \mathrm{H}$-imipramine binding in LSS fractions prepared from E20 rat brain. $A$, Saturation isotherm. Samples were incubated in the absence (open squares) or presence (solid circles) of $1 \mu \mathrm{m}$ norzimelidine. Specific binding (solid triangles) was defined as the total binding minus the binding in the presence of $1.0 \mu \mathrm{M}$ norzimelidine. $B$, Scatchard transformation (solid squares) of the specific binding of ${ }^{3} \mathrm{H}$-imipramine. A straight line was obtained $(R-0.99)$. Values are means of quadruplicate determinations in a typical experiment.

Synaptogenesis occurs mainly during postnatal periods. Since the cerebral cortex at E20 contains serotonergic growth cones, but not synapses, the presence of the 5-HT transporter in the cortex at this time would support the hypothesis that the transporter is present in growth cones. Radioautography was used to analyze the location of potential 5-HT uptake sites in prenatal rat cerebral cortex at E20. Both ${ }^{3} \mathrm{I}$-imipramine ( $11.0 \mu \mathrm{M}$ norzimelidine) and ${ }^{3} \mathrm{H}$-paroxetine $( \pm 30 \mu \mathrm{M}$ fluoxetine $)$ were used as probes. Specific ${ }^{3} \mathrm{H}$-imipramine and ${ }^{3} \mathrm{H}$-paroxetine binding sites were heterogeneously distributed in the brain at day E20. Binding sites were most concentrated in the region of the median raphe, septal nuclei, and the hypothalamus, but were also clearly present in the hippocampus and cerebral cortex (cingulate, fron-

\begin{tabular}{|c|c|c|}
\hline $\begin{array}{l}\text { Developmental } \\
\text { age }\end{array}$ & $\begin{array}{l}B_{\max } \pm \mathrm{SE} \\
(\mathrm{fmol} / \mathrm{mg})\end{array}$ & $\begin{array}{l}K_{d} \pm \mathrm{SE} \\
(\mathrm{nM})\end{array}$ \\
\hline E15 & $62.5 \pm 9.1$ & $2.65 \pm 0.20$ \\
\hline $\mathrm{E} 20$ & $147.0 \pm 7.0$ & $1.82 \pm 0.70$ \\
\hline P3 & $172.5 \pm 0.5$ & $1.62 \pm 0.32$ \\
\hline P7 & $185.0 \pm 13.5$ & $1.93 \pm 0.92$ \\
\hline P9 & $222.7 \pm 16.0$ & $1.88 \pm 0.54$ \\
\hline P13 & $196.7 \pm 24.6$ & $1.51 \pm 0.21$ \\
\hline P15 & $209.5+4.5$ & $1.47 \pm 0.25$ \\
\hline Adult $\left(\mathrm{P}_{2}\right)$ & $298.0 \pm 33.1$ & $1.54 \pm 0.28$ \\
\hline Adult (syn) & $353.0 \pm 14.0$ & $2.78 \pm 0.13$ \\
\hline
\end{tabular}

Data show kinetic characteristics of ${ }^{3} \mathrm{H}$-imipramine binding measured as a function of developmental age: the values represent means of three experiments; each experiment was done in quadruplicate. A nonlinear least-squares curve-fitling computer program (LuNDON-1) was used to estimate $B_{\max }$ and $K_{d}$. In all cases, a one-site model was best fitted to describe the data. Values were determined from the LSS fraction for ages E15-P15, while the mitochondrial pellet $\left(P_{2}\right)$ and synaptosomal fractions (syn) were used to determine the binding characteristics of ${ }^{3} \mathrm{H}$-imipramine in the adult. Data were analyzed statistically by an ANOVA. Differences in the $K_{v}$ between the different age groups were not significant.

tal, primary olfactory areas and the hippocampus) at this age (Figs. 4,5 ). The binding of ${ }^{3} \mathrm{H}$-imipramine to cortical sites was found to be highly dependent on the presence of $\mathrm{Na}^{+}$(Fig. 5). When $\mathrm{NaCl}$ was omitted from the incubating solution, binding was greatly reduced.

\section{$I G C$ fractions specifically accumulate ${ }^{3} \mathrm{H}-5-H T$}

In order to confirm that the 5-HT transporter is present on the plasma membrane of serotonergic growth cones, accumulation of ${ }^{3} \mathrm{H}-5-\mathrm{HT}$ was measured in IGC fractions prepared from rat brain at E15, E20, and P3. Inhibition of ${ }^{3} \mathrm{H}-5-\mathrm{HT}$ accumulation by fluoxetine, which blocks the uptake of 5-HT, but not that of norepinephrine, was used to define the specificity of ${ }^{3} \mathrm{H}-5-\mathrm{HT}$ uptake. The further addition of DMI $(0.1 \mu \mathrm{M})$, a drug that specifically blocks the uptake of norepinephrine, produced no additional antagonism of the accumulation of ${ }^{3} \mathrm{H}-5-\mathrm{HT}$. No specific uptake of ${ }^{3} \mathrm{H}-5-\mathrm{HT}$ was observed when IGC fractions were incubated at $0-4^{\circ} \mathrm{C}$. In contrast, when the assay was conducted at $37^{\circ} \mathrm{C}$, IGC fractions specifically accumulated ${ }^{3} \mathrm{H}-5-\mathrm{HT}$ for 5 min, after which equilibrium was reached. Specific uptake of ${ }^{3} \mathrm{H}-5-\mathrm{HT}$ was observed in IGC fractions as early as E15 and increased significantly between E15 and E20 (Fig. 6); however, no further increase was observed between E20 and P3. These data suggest that transmembrane transport of ${ }^{3} \mathrm{H}-5-\mathrm{HT}$ develops in IGC together with ${ }^{3} \mathrm{H}$-imipramine $/{ }^{3} \mathrm{H}$-paroxetine binding sites.

\section{Growth cones are the structures in IGC fractions that are responsible for uptake of ${ }^{3} \mathrm{H}-5-H T$}

The structures responsible for the uptake of ${ }^{3} \mathrm{H}-5-\mathrm{HT}$ in the IGC fraction at P3 were identified by EM radioautography. Fractions were incubated with ${ }^{3} \mathrm{H}-5-\mathrm{HT}$ as above; however, they were fixed so as to retain intracellular, but not extracellular, ${ }^{3} \mathrm{H}-5-\mathrm{HT}$ (Gershon and Ross, 1966). As a control, the IGC fraction was incubated with ${ }^{3} \mathrm{H}-5-\mathrm{HT}$ in the presence of fluoxetine. The grain distribution on the resulting EM radioautographs (Fig. 7) was analyzed statistically by the method of Williams (1969). For this purpose, three components were considered: (1) growth cones, (2) unoccupied space, and (3) un- 
Table 3. Enrichment of ${ }^{3} \mathrm{H}$-imipramine binding sites in IGC fractions

\begin{tabular}{|c|c|c|c|c|c|}
\hline \multirow[b]{2}{*}{ Age } & \multicolumn{3}{|c|}{$\begin{array}{l}{ }^{3} \mathrm{H} \text {-imipramine bound } \\
([\mathrm{fmol} / \mathrm{mg}] \pm \mathrm{SE})\end{array}$} & \multicolumn{2}{|c|}{$\begin{array}{l}n \text {-Fold enrichment } \\
\text { (over LSS) }\end{array}$} \\
\hline & LSS & IGC & $\mathrm{C}$ band & IGC & $\mathrm{C}$ band \\
\hline E15 & $38.36 \pm 5.9$ & $140.97 \pm 34.0$ & $47.69 \pm 10.5$ & $3.7^{*}$ & 1.24 \\
\hline $\mathrm{E} 20$ & $95.48 \pm 6.6$ & $228.43 \pm 37.2$ & $78.81 \pm 11.7$ & $2.4^{*}$ & 0.83 \\
\hline P3 & $134.30 \pm 9.5$ & $115.92 \pm 37.5$ & $93.43 \pm 5.9$ & 0.86 & 0.70 \\
\hline P7 & $133.12 \pm 10.2$ & $130.04 \pm 29.7$ & $84.54 \pm 9.4$ & 0.98 & 0.64 \\
\hline P27 & $110.49 \pm 39.9$ & $59.36 \pm 19.5$ & $101.38 \pm 55.2$ & 0.54 & 0.92 \\
\hline
\end{tabular}

Data show enrichment of ${ }^{3} \mathrm{H}$-imipramine binding in the growth cone fraction, and are shown relative to ${ }^{3} \mathrm{H}$-imipramine binding in the LSS as a function of developmental age. The concentration of ${ }^{3} \mathrm{H}$-imipramine was $6 \mathrm{~nm}$; nonspecific binding was estimated in the presence of $1 \mu \mathrm{M}$ norzimelidine. Each experiment was carried out in triplicate. The values represent means of three to five independent experiments. The $\mathrm{C}$ band was the fraction obtained at the $1.0-2.55 \mathrm{M}$ sucrose interface. Means were compared statistically by an ANOVA.

* ${ }^{3} \mathrm{H}$-imipramine binding in the IGC fraction was significantly enriched over that of the LSS $(p<0.05)$.

identified cell fragments (non-growth cones). A $\chi^{2}$ analysis was used to compare the number of silver grains associated with each of these components with the number predicted for a random distribution. The number expected for a random distribution was based on the measured effective areas of each item. The actual distribution of silver grains was found to differ significantly $(p<0.0001)$ from random (Table 4$)$. Only growth cones were associated with a significantly larger than random number of silver grains. The number of grains associated with space and structures that were not identifiable as growth cones was significantly less than that expected for a random distribution. The distribution of silver grains on EM radioautographs of scctions of IGC fractions incubated with ${ }^{3} \mathrm{H}-5-\mathrm{HT}$ in the presence of fluoxetine also differed significantly $(p<0.01)$ from that expected for a random distribution; however, in the presence of fluoxetine, the difference from random was due to a greater than expected abundance of silver grains associated with space, not growth cones. These data confirm that growth cones are the structures in the IGC fraction responsible for the specific (fluoxetine-sensitive) accumulation of ${ }^{3} \mathrm{H}-5-\mathrm{HT}$.

\section{5-HT, but not 5-HIAA, is retained within the IGC fraction}

Levels of 5-HT and 5-HIAA were measured in LSS and IGC fractions of developing pre- and postnatal rat brains. An extra step was added to the fractionation procedure in order to be certain that IGC fractions were not contaminated with supernatant material. This problem is important with regard to 5-HT because it is soluble. Breakage of 5-HT-containing cellular constituents would thus lead to the appearance of 5-HT in the supernatant fraction. Growth cones were therefore separated from supernatant material with a sucrose step gradient. The initial IGC fraction was diluted and loaded onto a two-step gradient consisting of a layer of $0.45 \mathrm{M}$ sucrose buffer and a cushion of Maxidens oil. Growth cones could thus be collected relatively quickly and were washed free of soluble contaminants as they sedimented through the $0.45 \mathrm{~m}$ sucrose layer. EM examination of the fraction collected over the Maxidens oil (data not illustrated) revealed its morphology to be essentially that of the IGC fractions described previously. Experiments in which known amounts of ${ }^{3} \mathrm{H}-5-\mathrm{HT}$ were added to IGC fractions (under conditions that prevented uptake of $\left.{ }^{3} \mathrm{H}-5-\mathrm{HT}\right)$ indicated that the purified IGC fraction was not significantly contaminated by material from the supernatant (see Materials and Methods).

5-HT and 5-HIAA were found to be present in both LSS (5HT, $5.8 \pm 0.3 \mathrm{pmol} / \mathrm{mg} ; 5$-HIAA, $6.0 \pm 0.4 \mathrm{pmol} / \mathrm{mg})$ and IGC (5-HT, $4.5 \pm 0.2 \mathrm{pmol} / \mathrm{mg} ; 5-\mathrm{HIAA}, 2.4 \pm 0.8 \mathrm{pmol} / \mathrm{mg})$ fractions as early as E15 (Fig. 8A). The concentrations of 5-HT in each of these fractions increased as a function of age during later development through $\mathrm{P} 9$. The increase in the levels of 5-HT in the IGC fractions (2.8-fold) was greatest between E15 and E20. The 5-HT concentration in the IGC fraction at P9 was significantly higher as a function of protein than that of synaptosomes prepared from adult brain $(p<0.05)$. Although the levels of 5-HT in the IGC fraction did not differ significantly from that of the LSS fraction at any of the ages tested, the concentration of 5-HIAA was significantly lower in the IGC than it was in the LSS fraction $(p<0.05)$ at all ages after E15 (Fig. $8 B$ ). As a result, the ratio of 5 -HT to 5-HIAA was substantially higher in the IGC than the LSS fraction (Fig. $8 C$ ). A similarly high ratio of 5-HT to 5-HIAA was found in synap-

Figure 4. Photographs of computer-assisted video images of sections through E20 rat brain. The densities of ${ }^{3} \mathrm{H}$-imipramine $(A, B)$ or ${ }^{3} \mathrm{H}$-paroxetine $(C-F)$ binding sites are represented in pseudocolor. Black, background; red, high density; purple, low density. $A$ and $B$, Adjacent sections incubated with $10 \mathrm{nM}{ }^{3} \mathrm{H}$-imipramine in the absence $(A)$ or presence $(B)$ of $1.0 \mu \mathrm{M}$ norzimelidine. The brain has been sectioned in an oblique plane, so the right half of each section is anterior to the left. Note that ${ }^{3} \mathrm{H}$-imipramine binding is displaced by norzimelidine. ${ }^{3} \mathrm{H}$-imipramine binding sites are concentrated in deeper layers of the frontal cortex. Less dense, but still specific, binding of ${ }^{3} \mathrm{H}$-imipramine is observed in the anterior olfactory area, olfactory tubercle $(O t u)$, and the cingulate cortex $(C g) . F C$, frontal cortex; Ins, insular cortex; Pir, piriform cortex; $A c b$, accumbens nucleus; $C P u$, caudate putamen. $C-F,{ }^{3} \mathrm{H}$-paroxetine binding sites in sections of fetal rat brain (E20). Sections were incubated with ${ }^{3} \mathrm{H}$-paroxetine (1.0 nM). Adjacent sections (illustrated in $F$ ) were incubated with ${ }^{3} \mathrm{H}$-paroxetine $(1.0 \mathrm{nM})$ and fluoxetine $(30 \mu \mathrm{M}) . C$, A coronal section reveals a high density of ${ }^{3} \mathrm{H}$-paroxetine binding sites in the cingulate cortex $(C g)$, anterior septum $(S)$, and anterior olfactory area $(A o a)$. $D$, A coronal section reveals a high density of ${ }^{3} \mathrm{H}$-paroxetine binding sites in the lateral region of the posterior hypothalamus $(P h)$ where the fibers of the median forebrain bundle $(m f b)$ are located. $E$, A midsagittal section reveals a high density of ${ }^{3} \mathrm{H}$-paroxetine binding sites in the brainstem and diencephalon $(D i e n)$. A particularly high level of ${ }^{3} \mathrm{H}$-paroxetine binding sites is present in the region of the raphe nuclei (arrow). A lower density of binding sites is observed in the frontal and posterior poles of the cerebral cortex (arrowheads). $F$, The binding of ${ }^{3} \mathrm{H}$-paroxetine is almost completely displaced by fluoxetine. $C b$, cerebellum; $D R$, dorsal raphe; $T$, tegmentum; $T h$, thalamus. 

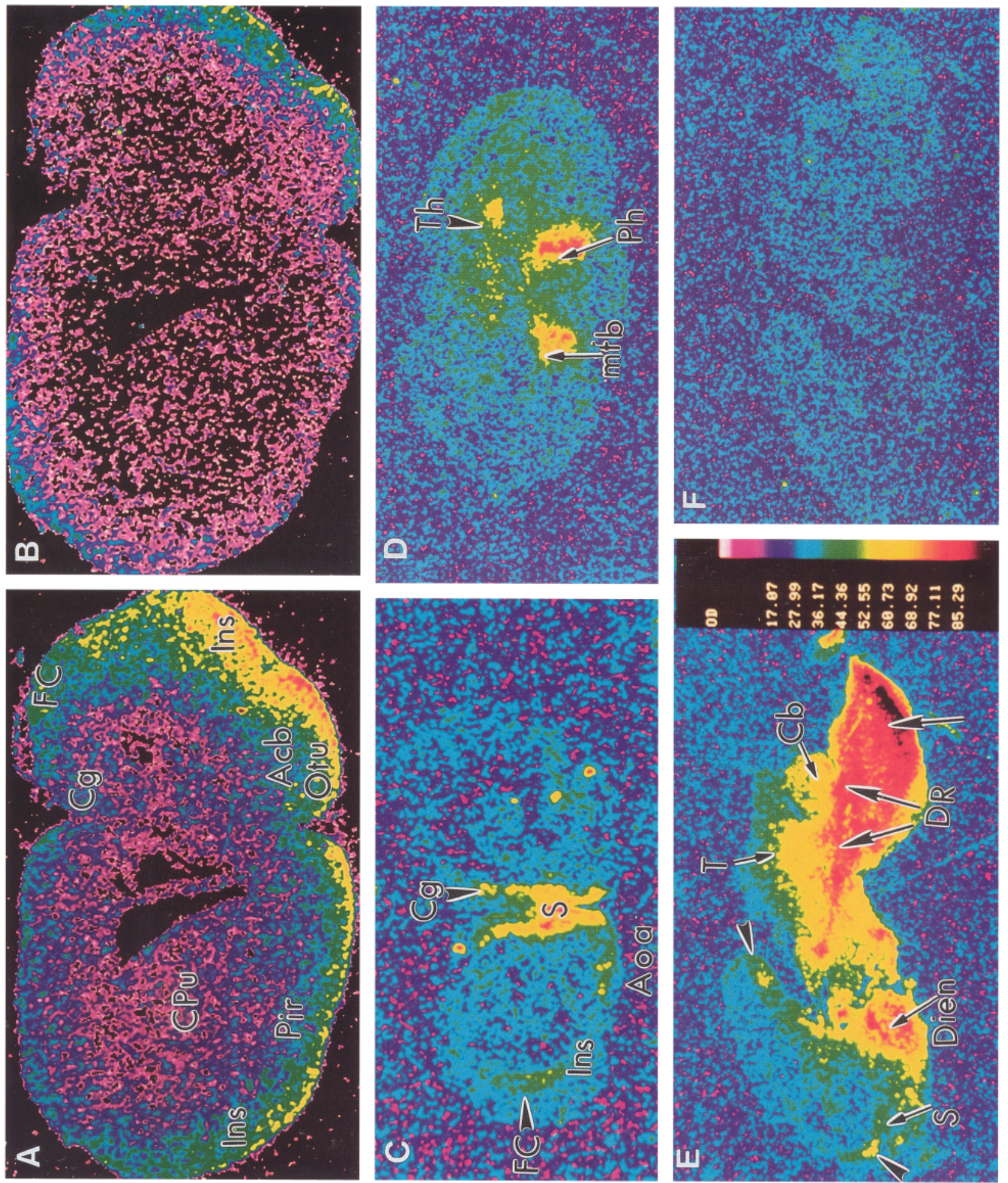

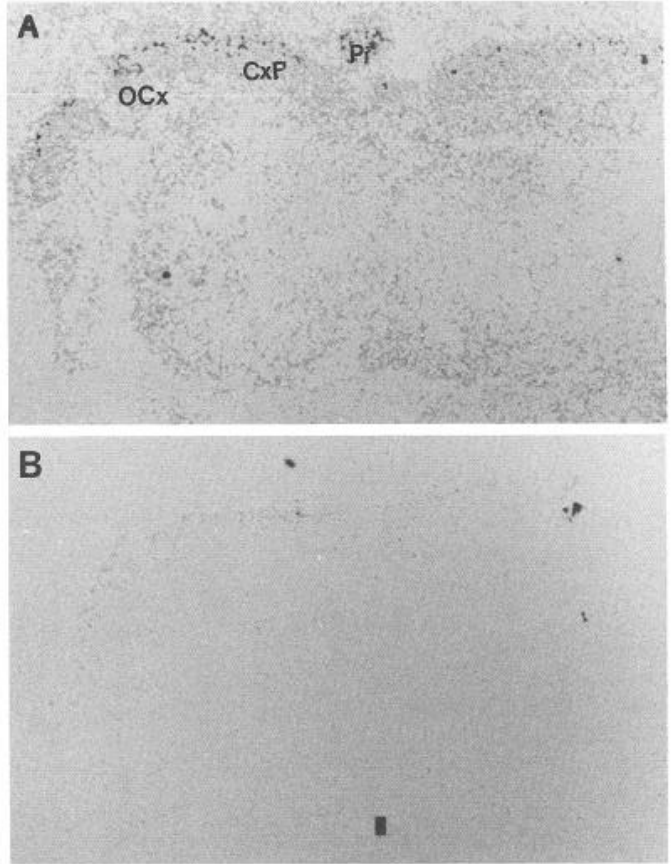

Figure 5. ${ }^{3} \mathrm{H}$-imipramine binding is sodium dependent. Frozen sections of fetal rat brain (E20) were incubated with $10 \mathrm{nM}$ of ${ }^{3} \mathrm{H}$-imipramine in the presence $(A)$ or absence $(B)$ of $120 \mathrm{nM} \mathrm{NaCl}$ in the incubation buffer. In the absence of $\mathrm{Na}^{+}$, the binding in the cerebral cortex and pineal gland is greatly reduced. $C X P$, cortical plate; $P i$, pineal gland; $O C x$, occipital cortex.

tosomes isolated from adult rat brains. These data suggest that 5-HT, but not 5-HIAA, is retained in growth cones.

\section{Depletion of endogenous 5-HT by reserpine}

The sensitivity of endogenous stores of 5-HT to depletion by reserpine was used as an indicator of the presence of vesicles that sequester 5-HT. The membrane of such vesicles can be assumed to contain the amine carrier (Liu et al., 1992), inhibition of which is known to be the action of reserpine. In the adult rat brain, a single injection of reserpine $(5 \mathrm{mg} / \mathrm{kg})$ causes a maximal depletion of 5 -HT $(\sim 90 \%)$ within $4 \mathrm{hr}$ (Carlsson, 1965). This effect is stable for at least $36 \mathrm{hr}$, after which the level of 5-HT begins to recover. In the present experiments, therefore, reserpine $(5 \mathrm{mg} / \mathrm{kg})$ was administered to pregnant dams $16 \mathrm{hr}$ before they were killed. Although at E15 reserpine significantly $(p<0.0001)$ lowered the 5-HT level in the LSS fraction (Fig. $9 A$ ), reserpine failed to deplete 5 -HT from the IGC fraction (Fig. $9 B$ ). In contrast to the results obtained at E15, at $\mathrm{E} 20(p<0.02)$ and $\mathrm{P} 3(p<0.02)$ reserpine significantly reduced the levels of 5-HT in IGC fractions (Fig. $9 B$ ). No reserpineinduced change in the levels of 5-HIAA in IGC fractions could be detected at any age until P3, at which time a significant rise (from $8.7 \pm 0.6 \mathrm{pmol} / \mathrm{mg}$ protein to $31.3 \pm 4.6 \mathrm{pmol} / \mathrm{mg}$ protein; $p<0.0001)$ was detected. These data indicate that a reserpine-depletable pool of 5-HT develops in serotonergic neurons by E15 and, between E15 and E20, appears in their growth cones.

\section{SBP immunoreactivity in brain fractions}

SBP immunoreactivity in rat brain fractions at E15, E20, P3, and P27 was assayed on immunoblots using monospecific poly-

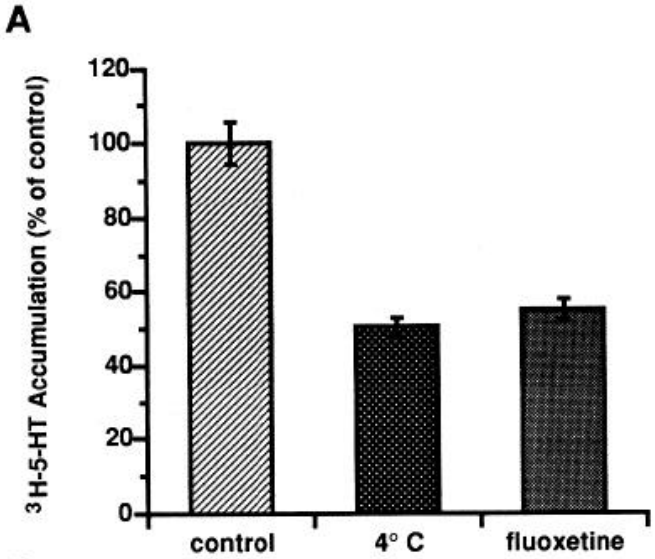

B

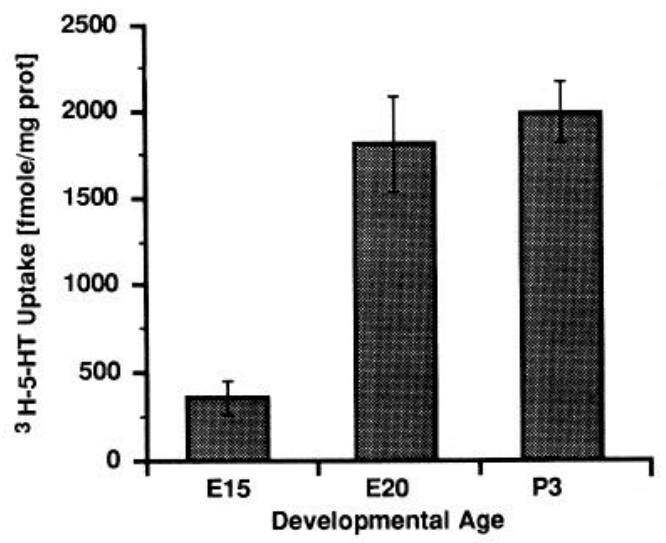

Figure 6. ${ }^{3} \mathrm{H}-5-\mathrm{HT}$ accumulation by IGC fractions. $A$, IGC fractions (prepared from rats at E20) were incubated with ${ }^{3} \mathrm{H}-5-\mathrm{HT}(0.5 \mu \mathrm{M})$ at $37^{\circ} \mathrm{C}$ or in the cold $\left(4^{\circ} \mathrm{C}\right)$. Fractions were also incubated at $37^{\circ} \mathrm{C}$ in the presence of $25 \mu \mathrm{M}$ fluoxetine. Data are expressed as percentage of control $\left(37^{\circ} \mathrm{C}\right.$, no drugs added). The values represent means of three different experiments \pm SE. Each experiment was done in triplicate. $B$, Uptake of ${ }^{3} \mathrm{H}-5$-HT was measured in IGC fractions in the absence or presence of fluoxetine at E15, E20, and P3. Uptake measured in the presence of fluoxetine was subtracted from that measured in its absence to determine specific accumulation of ${ }^{3} \mathrm{H}-5-\mathrm{HT}$. The histogram shows the specific accumulation of ${ }^{3} \mathrm{H}-5-\mathrm{HT}$ in the IGC fraction as a function of age. Values represent mean $\pm \mathrm{SE}$ of three independent experiments carried out in triplicate.

clonal antibodies directed against the $\sim 45 \mathrm{kDa}$ form of SBP. One major band of protein, corresponding in electrophoretic mobility to $43 \mathrm{kDa}$, reacted with these antibodies (Fig. 10). An additional minor band with an electrophoretic mobility corresponding to $32 \mathrm{kDa}$ was also immunoreactive. Both of these bands were detectable in LSS and IGC fractions as early as E15. Immunoreactivity in each of these fractions was more intense, however, at E20 and P3. At these ages, the immunoreactivity of the IGC fraction appeared to be greater than that of the LSS. In contrast, while the immunoreactivity of the 43 and $32 \mathrm{kDa}$ bands was also present at P27, that of the IGC fraction was now less than that of the LSS fraction or of synaptosomes (or the crude $\mathrm{P}_{2}$ fraction from which synaptosomes are derived). SBP immunoreactivity was also found in synaptosomes isolated from mature brains.

The distribution of the $32 \mathrm{kDa}$ band in subcellular fractions appeared to be similar to that of the major immunoreactive 43 $\mathrm{kDa}$ band. The $32 \mathrm{kDa}$ material also cross-reacted with three 

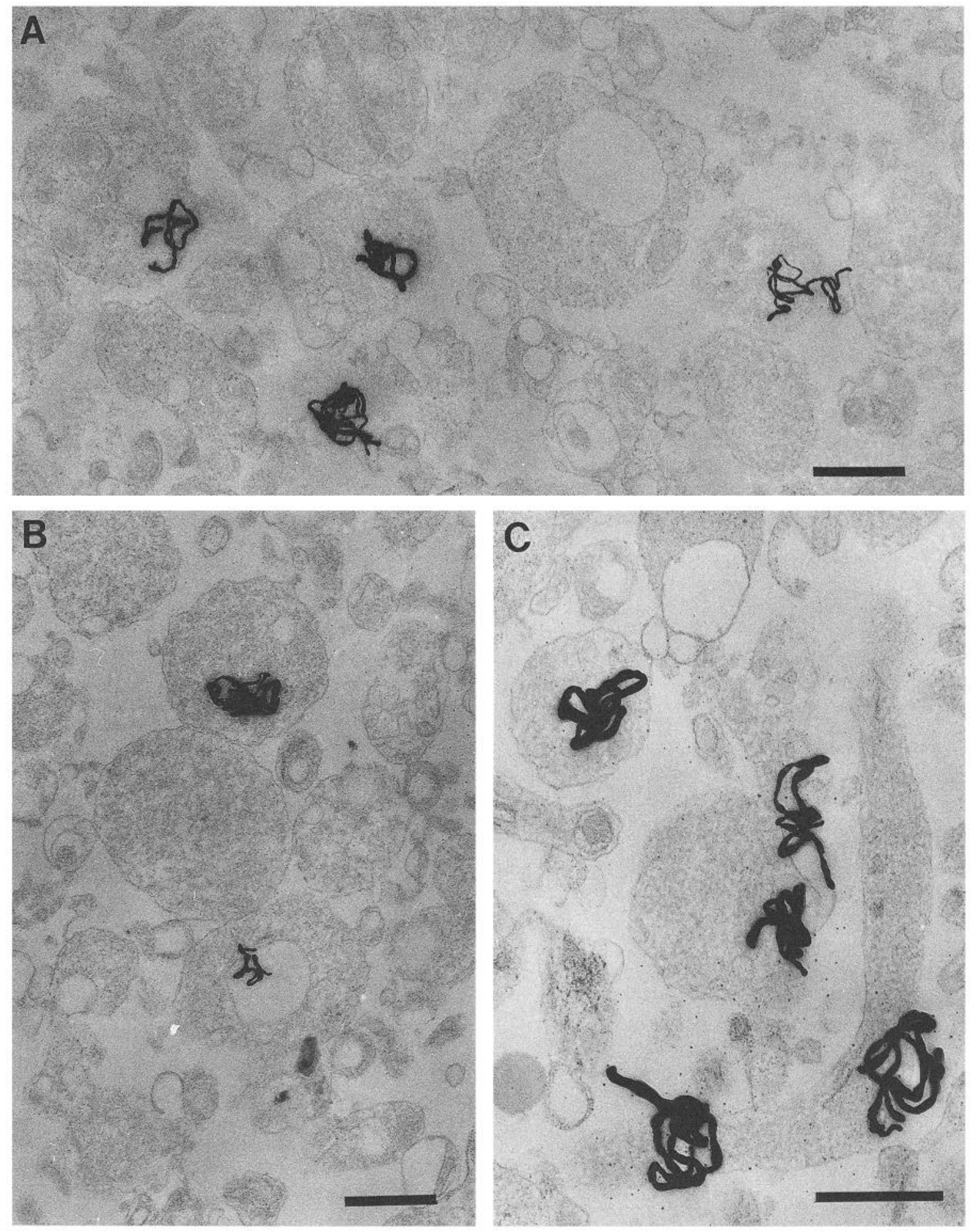

Figure 7. EM radioautographs of an IGC fraction (obtained from a rat brain at P3) that was incubated with ${ }^{3} \mathrm{H}-5-\mathrm{HT}$. $A-C$, Note that the radioautographic silver grains are found over membrane-enclosed cytoplasmic fragments that resemble growth cones. The distribution of radioautographic silver grains is analyzed in Table 4. Scale bars, $0.5 \mu \mathrm{m}$.

other polyclonal antibodies and one monoclonal antibody (Liu et al., 1990) prepared against $\sim 45 \mathrm{kDa}$ SBP (data not shown). These observations suggest that the $32 \mathrm{kDa}$ minor band may be a product of the degradation of the $43 \mathrm{kDa}$ protein. The amount of SBP immunoreactivity present in the fractions was estimated from the immunoblots with ${ }^{125} \mathrm{I}$-protein A. Separate determinations were made for the 43 and $32 \mathrm{kDa}$ bands. Values were normalized to that detected in the LSS fraction at E15 (the lowest detected) in each experiment. The sum of the immunoreactivities of the 32 and $43 \mathrm{kDa}$ bands was found to yield relative values similar to those of the $43 \mathrm{kDa}$ band itself. We therefore considered the $32 \mathrm{kDa}$ band to be derived from the $43 \mathrm{kDa}$ material and added the immunoreactivities of each to estimate the total SBP immunoreactivity present in each frac- 


\begin{tabular}{|c|c|c|c|c|}
\hline Structure & $\begin{array}{l}\text { Grains } \\
\text { expected } \\
\text { (random } \\
\text { distri- } \\
\text { bution) }\end{array}$ & $\begin{array}{l}\text { Grai } \\
\text { obse }\end{array}$ & & RSA \\
\hline \multicolumn{5}{|l|}{${ }^{3} \mathrm{H}-5-\mathrm{HT}$} \\
\hline Growth cones & 144 & 278 & 124.69 & 1.93 \\
\hline Space & 152 & 65 & 49.80 & 0.43 \\
\hline Non-growth cones & 64 & 17 & $\begin{array}{l}\frac{34.52}{\Sigma=209.01} \\
p<0.0001\end{array}$ & 0.27 \\
\hline \multicolumn{5}{|c|}{${ }^{3} \mathrm{H}-5-\mathrm{HT}+$ fluoxetine $(25 \mu \mathrm{M})$} \\
\hline Growth cones & 75 & 50 & 8.33 & 0.67 \\
\hline Space & 58 & 92 & 19.93 & 1.6 \\
\hline Non-growth cones & 19 & 10 & $\begin{array}{l}\frac{4.26}{\Sigma=32.53} \\
p<0.01\end{array}$ & 0.52 \\
\hline
\end{tabular}

Data show statistical analysis of the distribution of silver grains in EM radioautographs. IGC fractions incubated with ${ }^{3} \mathrm{H}-5-\mathrm{HT}$ alone are compared with material incubated with ${ }^{3} \mathrm{H}-5-\mathrm{HT}+$ fluoxetine. Grain distribution was compared with that of random circles by means of $\chi^{2}$. The relative specific activity (RSA) is defined as the percentage of grains associated with a component divided by the percentage of random circles associated with the same component. Areas occupied by the different components were estimated by point count planimetry. For the fractions incubated with ${ }^{3} \mathrm{H}-5-\mathrm{HT}$ alone, 360 silver grains, 1176 circles, and 3075 points were included in the analysis. For the fractions incubated with ${ }^{3} \mathrm{H}-5-\mathrm{HT}$ in the presence of fluoxetine, 152 silver grains, 873 circles, and 1740 points were included in the analysis.

tion. These values are summarized in Table 5. Note that SBP immunoreactivity increased considerably during the period studied, with the most pronounced increase uccurring postnatally (the increase between E20 and P27 is ninefold). On E15, E20, and P3 the IGC fraction contained a significantly higher level of SBP immunoreactivity than did its corresponding LSS fraction. The amount of SBP-immunoreactive material in the IGC fraction declined relative to that in the LSS at P27. At P27 serotonergic synaptogenesis is largely complete (Lidov and Molliver, 1982a); therefore, at P27 and later, SBP should be found in synaptosomes instead of growth cones. At P27 SBP was found in synaptosomes, where its level was about 70-fold higher than that detected in the reference LSS fraction from E1 5 fetal brain.

\section{Synaptophysin immunoreactivity in brain fractions}

Synaptophysin (p38) immunoreactivity in rat brain fractions at $\mathrm{E} 15$, E20, and P15 was assayed on immunoblots using monospecific polyclonal antibodies (Jahn et al., 1985). One major band of protein, corresponding in electrophoretic mobility to $\sim 38 \mathrm{kDa}$, reacted with these antibodies (Fig. 11). An additional minor band with an electrophoretic mobility corresponding to $\sim 76 \mathrm{kDa}$ was also immunoreactive. Synaptophysin immunoreactivity was detectable in LSS and IGC fractions as early as E15 (inset of Fig. 11). Immunoreactivity in each of these fractions was more intense, however, at E20. At E15 and E20 the immunoreactivity of the IGC fraction appeared to be greater than that of the LSS. In contrast, synaptophysin immunoreactivity of the IGC fraction at P27 was less than that of the LSS fraction and that of synaptosomes (which could be obtained at this age). The level of synaptophysin immunoreactivity in fractions of developing brain was estimated by dot immunobinding.

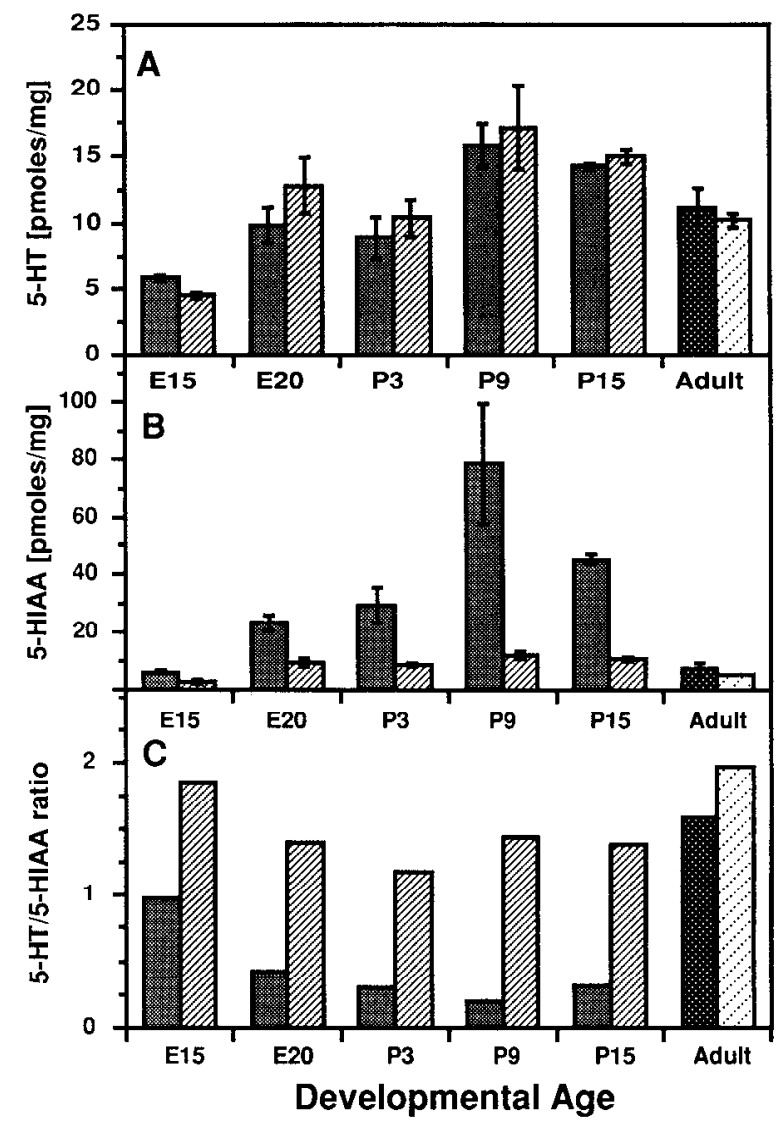

Figure 8. Levels of endogenous 5-HT and 5-HIAA in brain fractions as a function of developmental age. LSS (shaded bars) and IGC (hatched bars) fractions were prepared from developing brain; crude $\mathrm{P}_{2}$ (Adult, black bars with white dots) and synaptosomal (white bars with black $d o t s$ ) fractions were prepared from adult brains. A, 5-HT (pmoles $/ \mathrm{mg}$ ). $B, 5$-HIAA (pmoles/mg). $C$, Ratio of the level of 5-HT to that of 5-HIAA. Values represent means \pm SE of three to five independent measurements, each carried out in duplicate.

As was done with SBP, values were normalized to that detected in the LSS fraction at E15 (the lowest detected) in each experiment. These data, which include P15, are summarized in Table 6. Note that, as was also observed in studies of SBP immunoreactivity, synaptophysin immunoreactivity increased considerably between E15 and P27; the most pronounced increase again occurred postnatally (the increase between E20 and P27 is fivefold). On E15 and E2O the IGC fraction contained a significantly higher level of synaptophysin immunoreactivity than did the corresponding LSS fraction. Synaptophysin immunoreactivity was about equal in the two fractions at P15, and at P27 the amount of synaptophysin-immunoreactive material in the IGC fraction was lower than that in the LSS. At P27 synaptophysin immunoreactivity was found in synaptosomes, where its level was about 30-fold higher than that detected in the reference LSS fraction from E15 fetal brain.

Synaptophysin immunoreactivily was assayed in fractions prepared from the brains of E20 rats treated with reserpine in order to evaluate the specificity of the action of the drug. $\mathrm{Re}$ serpine failed to cause a significant change in the level of synaptophysin immunoreactivity in either the LSS or the IGC fraction. Reserpine thus does not affect all membrane proteins in the vesicles of growth cones; therefore, its action on the 5-HT 


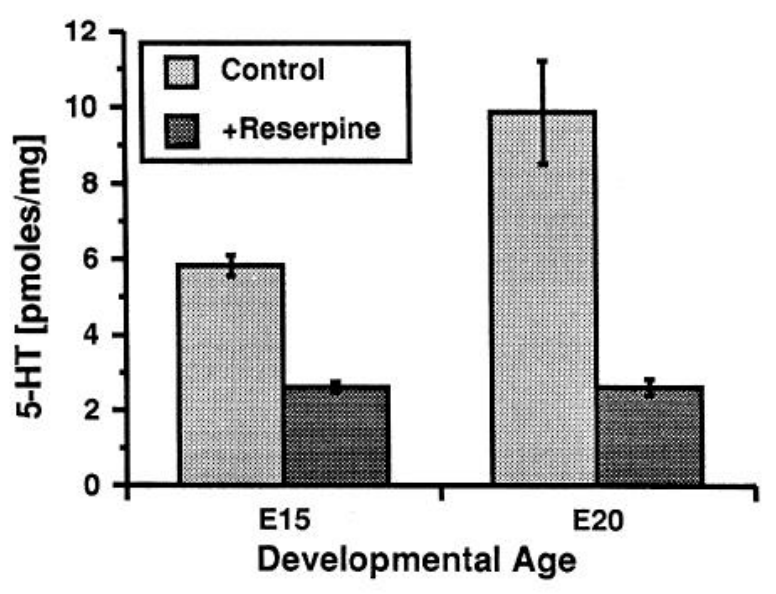

A

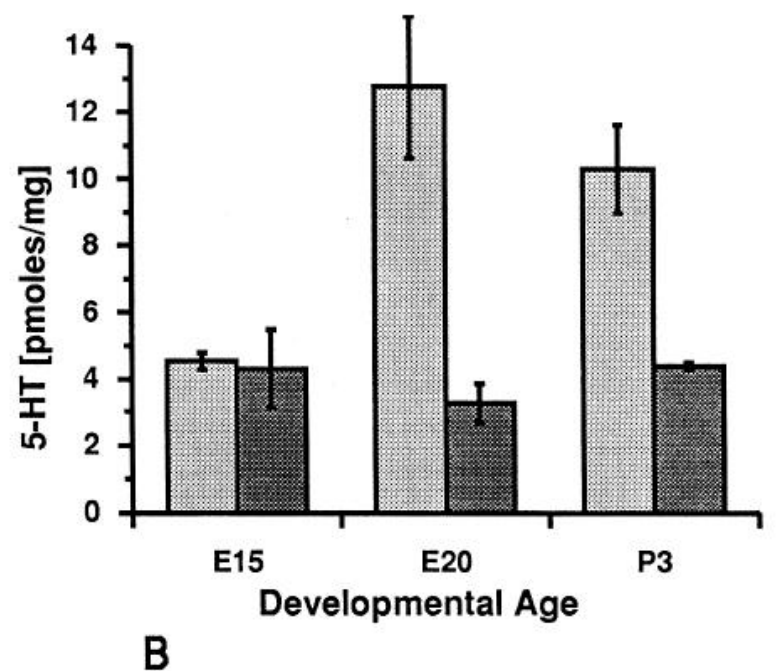

Figure 9. Effect of reserpine $(5.0 \mathrm{mg} / \mathrm{kg})$ on the level of endogenous 5-HT. A, LSS fraction. $B$, IGC fraction. At E1 5 reserpine depleted 5-HT from the LSS, but not the IGC fraction. After E20 reserpine depleted 5 -HT from both fractions. Values represent means \pm SE of three independent experiments, each carried out in duplicate.

carrier in growth cones (permitting 5-HT to be catabolized), like its similar action at mature synapses, is specific.

\section{GAP43 immunoreactivity in brain fractions}

The immunoreactivity of GAP43 ("neuromodulin") in IGC fractions at E15, E20, P3, and P27 was assayed on immunoblots using monoclonal antibodies (Goslin et al., 1988, 1990). For comparison, synaptosomal fractions from $\mathrm{P} 3$ and adult brains were also assayed. GAP43 was analyzed because it is known to be associated with axonal growth and to be present in axonal growth cones (Meiri et al., 1986; Skene et al., 1986). One band of protein, corresponding in electrophoretic mobility to $\sim 57$ $\mathrm{kDa}$, reacted with these antibodies (Fig. 12). GAP43 immunoreactivity was found in the IGC fraction at days E15 and E20. At both of these ages, GAP43 immunoreactivity was enriched in the IGC fraction relative to the LSS fraction. In contrast, very little GAP43 immunoreactivity could be found in either the IGC or synaptosomal fraction at P27.

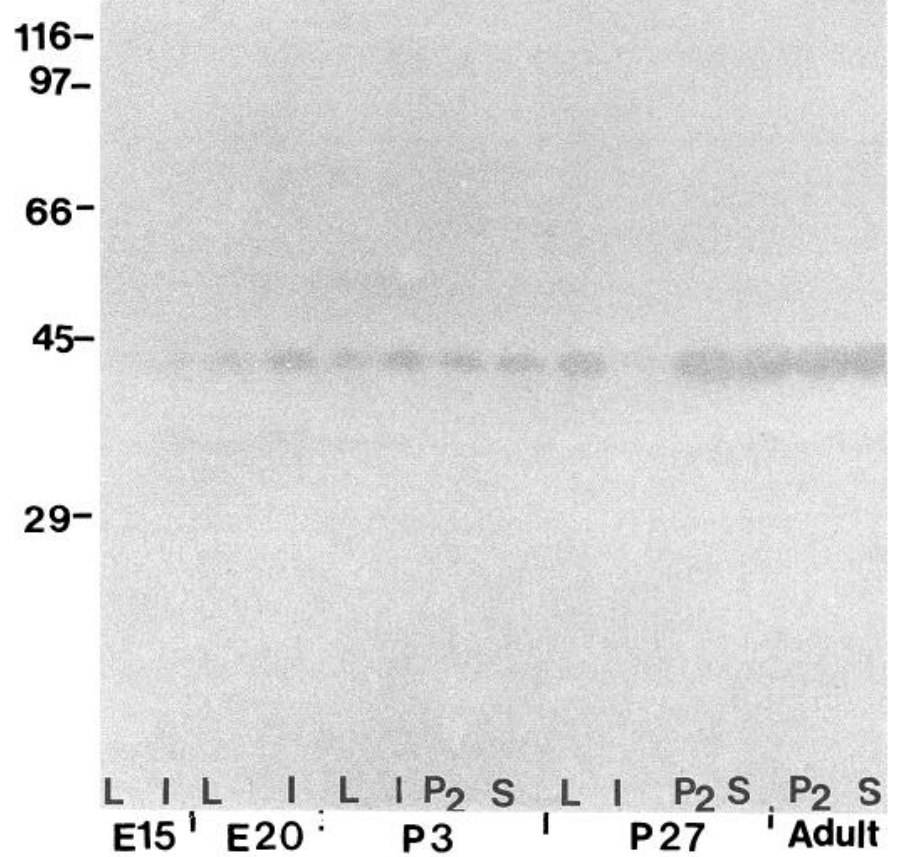

Figure 10. Immunoblot showing the distribution of SBP immunoreactivity in brain fractions as a function of age during development. Equal amounts of proteins $(50 \mu \mathrm{g})$ were loaded onto each lane. The designated fractions are as follows: $L$, LSS; $I$, IGC; $P_{2}$, crude fraction from which synaptosomes are prepared; $S$, synaptosomes. The position of the molecular mass standards is shown on the left. Note the enrichment, relative to the comparable LSS fraction, of SBP immunoreactivity in the IGC fraction at E15, E20, and P3. Note also that the relative intensity of SBP immunostaining is diminished, relative to the comparable LSS fraction, in the IGC fraction at P27.

\section{Discussion}

The primary objective of this study was to determine whether specific characteristics of mature serotonergic axon terminals are present in the growth cones of these neurons prior to synaptogenesis. We thus attempted to determine whether or not the plasma membrane of the growth cones of developing serotonergic neurons contains the specific 5-HT transporter and whether or not the growth cones store 5-HT in vesicles of the synaptic type. The 5 -HT transporter is found specifically in

\section{Table 5. SBP immunoreactivity in rat brain subcellular fractions during development}

Devel- Relative binding of ${ }^{125} \mathrm{I}$-protein A

opmen- to subcellular fractions

\begin{tabular}{lccll} 
tal age & LSS & IGC & $\mathrm{P}_{2}$ & Synaptosome \\
\hline E15 & 1.0 & $3.5 \pm 0.9^{*}$ & - & - \\
E20 & $3.5 \pm 0.4$ & $16.9 \pm 1.1^{*}$ & - & - \\
P15 & $10.4 \pm 1.7$ & $23.6 \pm 2.7^{*}$ & $15.4 \pm 0.1$ & $19.0 \pm 0.7$ \\
P27 & $31.0 \pm 0.7$ & $21.5 \pm 0.3^{*}$ & $59.7 \pm 10.5$ & $68.3 \pm 8.2$ \\
Adult & - & - & $66.4 \pm 13.9$ & $63.7 \pm 10.8$
\end{tabular}

Data show SBP immunoreactivity in brain fractions was analyzed by measuring the amount of ${ }^{125}$ I-protein A bound to SBP-immunoreactive bands on Western blots. Values were normalized to that of the LSS fraction at E15 within each experiment. Means $\pm \mathrm{SE}$ of three independent experiments are given. The data were evaluated by means of Student's $t$ test.

* Significantly $(p<0.05)$ different than the corresponding LSS fraction. 


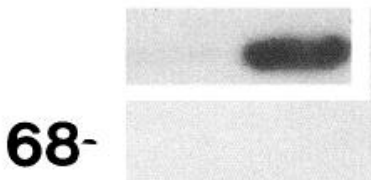

Figure 11. Immunoblot showing the distribution of synaptophysin immunoreactivity in brain fractions as a function of age during development. Equal amounts of proteins $(60 \mu \mathrm{g})$ were loaded onto each lane. The designated fractions are as follows: $L$, LSS; $I$, IGC; $P_{2}$, crude fraction from which synaptosomes are prepared; $S$, synaptosomes. The position of the molecular mass standards is shown on the left. Note the enrichment, relative to the comparable LSS fraction, of synaptophysin immunoreactivity in the IGC fraction at E15 and E20. The inset shows a longer exposure of the blot to demonstrate the immunoreactivity of synaptophysin in the LSS and IGC fractions at E20.

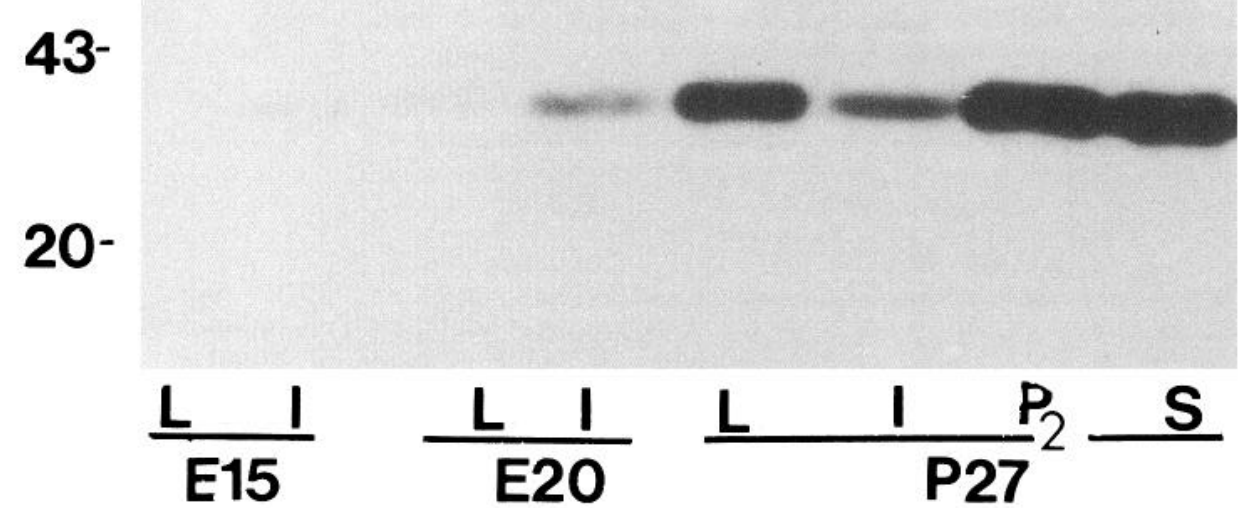

serotonergic neurons (Ross, 1982; Blakely et al., 1991; Hoffman et al., 1991). In contrast, the amine transporter in the membranes of serotonergic synaptic vesicles is not 5-HT specific, and is common to neurons that utilize a monoamine as their transmitter (Liu et al., 1992). The synaptic vesicles of serotonergic neurons differ, however, from those of other types of monoaminergic neuron in that only the synaptic vesicles of serotonergic neurons contain $45 \mathrm{kDa}$ SBP (Jonakait et al., 1979; Tamir and Gershon, 1979; Gershon et al., 1983; Gershon and Tamir, 1984, 1985; Barasch et al., 1987; Kirchgessner et al., 1988; Tamir et al., 1990). In order to obtain growth cones for study, developing rat brains were homogenized and IGC fractions were prepared. The IGC fraction was characterized first; subsequently, markers were evaluated in the IGC fraction for the specific plasma membrane 5-HT transporter and for serotonergic synaptic vesicles.

The IGC fraction was characterized by EM because there are no accepted biochemical markers for growth cones. Preparations obtained from postnatal animals were found to be morphologically similar to the prenatal preparations described earlier (Pfenninger et al., 1983; Lockerbie, 1990). The IGC fractions were highly enriched in cellular fragments, the appearance of which resembled that of growth cones in situ (Cheng and Reese,

\begin{tabular}{|c|c|c|c|}
\hline \multirow{2}{*}{$\begin{array}{l}\text { Devel- } \\
\text { opmen- } \\
\text { tal age }\end{array}$} & \multicolumn{3}{|c|}{$\begin{array}{l}\text { Relative binding of }{ }^{125} \mathrm{I} \text {-protein } \mathrm{A} \\
\text { to subcellular fractions }\end{array}$} \\
\hline & LSS & IGC & $\mathrm{P}_{2}$ \\
\hline E15 & $1.0 \pm 0.2$ & $3.4 \pm 0.4^{*}$ & - \\
\hline E20 & $4.6 \pm 0.3$ & $7.5 \pm 0.7^{*}$ & - \\
\hline P15 & $16.0 \pm 1.6$ & $20.7 \pm 2.6$ & $25.3 \pm 2.9$ \\
\hline P27 & $22.2 \pm 1.9$ & $10.4 \pm 0.5^{*}$ & $30.2 \pm 3.8$ \\
\hline Adult & - & - & $44.4 \pm 2.5$ \\
\hline
\end{tabular}

Synaptophysin immunoreactivity in brain fractions was analyzed by measuring the amount of ${ }^{125} \mathrm{I}$-protein $\mathrm{A}$ bound in a dot immunobinding assay. Values were normalized to that of the LSS fraction at E15 within each experiment. Means \pm $\mathrm{SE}$ of three independent experiments are given. The data were evaluated by means of Student's $t$ test.

* Significantly $(p<0.05)$ different than the corresponding LSS fraction.
1985; Bray and Hollenbeck, 1988). The absence of internal ribosomes and arrays of intermediate filaments as well as the relative paucity of GFAP immunoreactivity suggested that the cellular fragments were primarily derived from axons and not glia. Since bundles of microtubules were also lacking in the IGC cellular fragments, the fragments are probably derived mainly from the terminal ends of axons and not their shafts. The relatively high phospholipid-to-protein ratio found in the IGC fraction is also consistent with the idea that the fraction contains growth cones, which are rich in internal membranes. These membranes, moreover, were not derived from either the endoplasmic reticulum or the Golgi apparatus, since markers for these organelles (rough microsomes and galactosyltransferase activity) were impoverished in the IGC fraction. Furthermore, the experimental result (see discussion below), that the neuronal

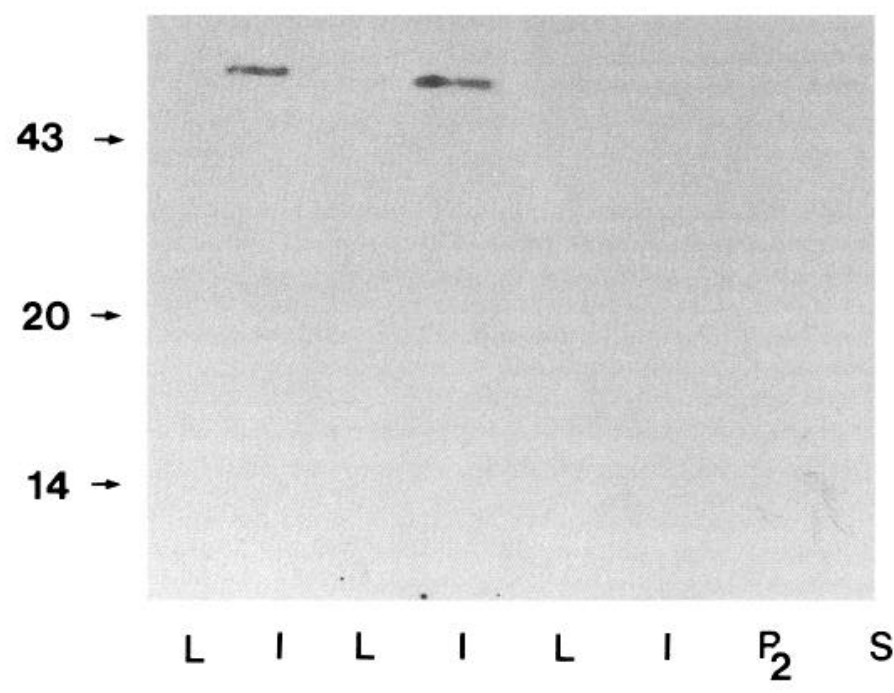

Figure 12. Immunoblot showing the distribution of GAP43 immunoreactivity in brain fractions as a function of age during development. Equal amounts of proteins $(60 \mu \mathrm{g})$ were loaded onto each lane. The designated fractions are as follows: $L$, LSS; $I$, IGC; $P_{2}$, crude fraction from which synaptosomes are prepared; $S$, synaptosomes. Molecular weight markers are indicated at the left. 
5-HT transporter is concentrated in the IGC fraction, also indicates that this fraction is primarily derived from neurons. The enrichment, relative to the LSS, of GAP43 found in IGC fractions at E15 and E20 supports the conclusion based on morphological evidence that growth cones are concentrated in IGC fractions. The loss of GAP43 from the IGC fraction at P27 is consistent with the idea that growth cones are no longer present in the fraction at this age. Finally, when mature synaptosomes were added to homogenates they did not sediment in the IGC fraction. The development of mature synapses, therefore, is unlikely to confound studies that utilize IGC fractions to investigate the properties of growth cones. It was thus concluded that IGC fractions are suitable for the study of axonal growth cones.

The binding of ${ }^{3} \mathrm{H}$-imipramine or ${ }^{3} \mathrm{H}$-paroxetine was used to detect the 5-HT transporter. The sites to which ${ }^{3} \mathrm{H}$-imipramine binds with high affinity and $\mathrm{Na}^{+}$dependence have been shown to be present on serotonergic axons (Sette et al., 1981; Briley, 1985; Severson et al., 1986) and, more recently, to be the 5-HT recognition site of the 5-HT transporter (Hrdina, 1988; Graham et al., 1989). Specific binding of ${ }^{3} \mathrm{H}$-imipramine was detected at E15, the earliest age tested, and at all ages thereafter. The $B_{\max }$ for ${ }^{3} \mathrm{H}$-imipramine binding increased as a function of age, while the $K_{d}$ did not change; therefore, development is evidently associated with an increase in the number of binding sites and not with a change in binding affinity. Only a single class of highaffinity binding sites was observed, the Hill coefficient was close to 1 , and the values for $K_{d}(1.5-2.65 \mathrm{nM})$ were not significantly different from values reported for ${ }^{3} \mathrm{H}$-imipramine binding in adult rat ( $\sim 4 \mathrm{~nm}$; Marcusson et al., 1986, 1988) or human brain ( $2.8 \mathrm{nM}$; Bäckström and Marcusson, 1987). The similarity of the properties of ${ }^{3} \mathrm{H}$-imipramine binding in the developing brain to that of adults suggests that ${ }^{3} \mathrm{H}$-imipramine binding is a marker for the 5-HT transporter in developing as well as adult brain.

Specific high-affinity ${ }^{3} \mathrm{H}$-imipramine binding sites were observed to be enriched in the IGC fraction at E15 and E20, agcs that precede the formation of serotonergic synapses in the forebrain (Lidov and Molliver, 1982a). Measurement of the binding of ${ }^{3} \mathrm{H}$-imipramine in fractions was supplemented by the radioautographic localization of ${ }^{3} \mathrm{H}$-imipramine and ${ }^{3} \mathrm{H}$-paroxetine binding sites in sections of brain. E20 was selected for detailed radioautographic study because it is a time when serotonergic axons have been reported to be present in the cortex, but have not yet begun to form synapses (Lidov and Molliver, 1982a). At E20, therefore, the cortex should contain growth cones, but not synapses. As a result, the observation, even at the light microscopic level, of ${ }^{3} \mathrm{H}$-imipramine and ${ }^{3} \mathrm{H}$-paroxetine binding sites in the cortex at E20 would suggest that growth cones contain the 5-HT transporter. Qualitatively similar results were obtained with ${ }^{3} \mathrm{H}$-imipramine and ${ }^{3} \mathrm{H}$-paroxetine, although with ${ }^{3} \mathrm{H}$-paroxetine more than $90 \%$ of the total binding was found to be specific. The pattern of ${ }^{3} \mathrm{H}$-paroxetine binding sites observed by radioautography corresponded closely to the distribution of serotonergic axons previously described by histofluorescence (Seiger and Olson, 1973) or immunohistochemistry (Lidov and Molliver, 1982a). As expected, at E20 ${ }^{3} \mathrm{H}$-paroxetine binding sites were most concentrated within the region of the median raphe, where serotonergic terminals are highly concentrated (Lidov and Molliver, 1982b; Kirchgessner et al., 1988). In addition to the raphe, however, significant ${ }^{3} \mathrm{H}$-imipramine and ${ }^{3} \mathrm{H}$-paroxetine binding was also observed more rostrally, in locations that included the cerebral cortex. These observations are consistent with the idea that ${ }^{3} \mathrm{H}$-imipramine $/{ }^{3} \mathrm{H}$-paroxetine binding sites, and thus the 5-HT transporter, are present on or in the growth cones of serotonergic axons.

Since serotonergic neurons are among the earliest neurons of the rat brain to differentiate and extend axons (Olson and Seiger, 1972; Seiger and Olson, 1973; Lauder and Bloom, 1975), it was anticipated that subcellular fractions prepared from brains of fetal animals early in development would contain proportionally more serotonergic elements than would similar fractions prepared from brains at later ages. As development proceeds and nonserotonergic neurons come to comprise an increasing proportion of the brain parenchyma, the degree to which the content of subcellular fractions is derived from serotonergic elements would be expected to diminish. With respect to the IGC fraction, this relative decline would accentuate that caused by the formation of serotonergic synapses. Synaptosomes, when they were added to homogenates, did not cosediment with growth cones. Neither of these considerations, however, seems able to account fully for the extensive enrichment of ${ }^{3} \mathrm{H}$-imipramine binding sites in the early IGC fractions at E15 and E20, which was noted relative to the LSS fractions prepared from the same brains and from which the IGC fractions were derived. This enrichment suggests that, as in synaptosomes (Rehavi et al., 1983; Briley, 1985), ${ }^{3} \mathrm{H}$-imipramine binding sites are more concentrated in growth cones than they are in other regions of serotonergic neurons.

The ability of IGC fractions to accumulate ${ }^{3} \mathrm{H}-5$-HT itself was investigated as a function of age. This was done because, in the absence of additional information, it is impossible to judge from biochemical or radioautographic studies of ${ }^{3} \mathrm{H}$-imipramine or ${ }^{3} \mathrm{H}$-paroxetine binding whether the binding sites are internal or on growth cone surfaces; therefore, it is important to know not only whether or not the transporter is present, but whether it is functional. IGC fractions were found to accumulate ${ }^{3} \mathrm{H}-5$-HT specifically as early as E15. Since far more ${ }^{3} \mathrm{H}-5-\mathrm{HT}$ (on a molar basis) became associated with IGC fractions than ${ }^{3} \mathrm{H}$-imipramine, ${ }^{3} \mathrm{H}-5$-HT must have been transported into growth cones and not simply bound to their surfaces. The ${ }^{3} \mathrm{H}-$ 5-HT: ${ }^{3} \mathrm{H}$-imipramine ratio was 2.6 at E15, 7.9 at E20, and 17.2 at $\mathrm{P} 3$. The increase in this ratio as a function of age may indicate that the internal ability of growth cones to store 5-HT increases more during ontogeny than the ability of the growth cone plasma membrane to transport 5-HT. The suggestion that growth cones themselves actually accumulate ${ }^{3} \mathrm{H}-5-\mathrm{HT}$ was supported by EM radioautography, which also revealed that the internalization of ${ }^{3} \mathrm{H}-5-\mathrm{HT}$ by these structures was inhibited by fluoxetine. These observations are consistent with the conclusions that the 5-HT transporter is responsible for the accumulation of ${ }^{3} \mathrm{H}-5-\mathrm{HT}$ in IGC. It can thus be concluded that the early presence of ${ }^{3} \mathrm{H}-$ imipramine $/{ }^{3} \mathrm{H}$-paroxetine binding sites correlates with the presence of a functional 5-HT transporter in the plasma membrane of the axonal growth cones of serotonergic neurons.

Earlier studies have shown that elements of the developing brain or subcellular fractions take up ${ }^{3} \mathrm{H}-5-\mathrm{HT}$ prior to the age when serotonergic synapses are formed (Yamamoto et al., 1981; Reisert et al., 1989; Ugrumov et al., 1989; Lockerbie et al., 1991); however, these prior observations did not show that the 5-HT transporter was actually present in the plasma membranes of serotonergic growth concs. Scrotoncrgic growth concs arc probably not unique in their ability to take up a neurotransmitter. Isolated growth cones have also been found to accumulate ${ }^{3} \mathrm{H}-\mathrm{GABA}$ or ${ }^{3} \mathrm{H}$-noradrenaline (Gordon-Weeks et al., 1984; Lockerbie et al., 1985). The accumulation of ${ }^{3} \mathrm{H}-\mathrm{GABA}$ 
by growth cones has also been confirmed by EM radioautography (Taylor and Gordon-Weeks, 1989).

Enrichment of vesicular markers in the IGC fraction relative to their concentration in the LSS fraction was investigated in order to determine whether growth cones contain synaptic vesicles. 5-HT and 5-HIAA were each found to be present in IGC and LSS fractions as early as E15. The ratio of 5-HT to 5-HIAA in the IGC fraction was greater than 1 at each age examined. These data suggest that growth cones retain 5 -HT, but not 5-HIAA. Retention of 5-HT within growth cones is compatible with, but not proof of, the idea that these structures contain vesicles that are able to sequester 5-HT. Growth cones contain mitochondria (Landis, 1983), mitochondria contain MAO (Greenawalt, 1972; Gershon et al., 1990), and MAO is known to have developed in the fetal rat brain prior to E15 (Schmidt and Sander-Bush, 1971; Hamon and Bourgoin, 1982; Liu et al., 1987). In order to retain 5-H l, therefore, growth cones must be able to prevent its catabolism by MAO. 5-HT could be protcetcd by scquestration within synaptic vesicles. If so, then reserpine, by inhibiting the action of the vesicular transporter, should deplete growth cone 5-HT. Since reserpine depleted 5-HT from the LSS fraction as early as E15, vesicles with an amine carrier have presumably been acquired by serotonergic neurons by E15. The failure of reserpine to deplete 5-HT in the IGC fraction at this age suggests that although these vesicles are present elsewhere in serotonergic neurons at E15, they are not present in growth cones. Unlike mature neurons, where synaptic vesicles and their proteins are concentrated in axon terminals and are sparse in preterminal axoplasm (De Camilli and Jahn, 1990), synaptic vesicles, or antigens associated with them, have been found to be distributed throughout the axons of developing neurons (Bixby and Reichardt, 1985; Mason, 1986; Chun and Shatz, 1988; Leclerc et al., 1989; Lupa and Hall, 1989; Fletcher et al., 1991). In contrast to E15, reserpine administration on E20 was effective in depleting 5-HT from the IGC fraction; thus, by E20, vesicles with an amine carrier are likely to have moved into growth cones. The developmental change between $\mathrm{E} 15$ and E20 could arise if serotonergic neurons become more mature or if the population of growth cone collected at E1 5 is different from that collected at E20 and subsequently. It is not clear why, if sequestering vesicles are absent, the IGC fraction should contain any 5-IIT at all. It is possible that some cytosolic 5-IIT within growth cones may be protected by binding to soluble SBP ( 56 and $68 \mathrm{kDa}$ ), which has been found in the brain (Liu et al., 1990). MAO does not catabolize 5-HT that is bound to these proteins (Liu et al., 1987). More likely, the cytosol of growth cones at E15 may contain a small amount of 5-HT, which reflects a balance between opposing rates of synthesis and degradation. Such a steady state would not be altered by reserpine. This explanation is supported by the observation that when 5-HT was depleted from IGC fractions by reserpine administered at E20, the residual 5-HT concentration remaining in the fractions did not differ significantly from that observed in IGC fractions prepared from animals at E15 (see Fig. 4). Whatever the explanation for the small amount of 5-HT present in growth cones at EI S, the effect of reserpine on the fetal brain is consistent with the idea that substantial numbers of vesicles of the synaptic type enter growth cones between E15 and E20.

The idea that growth cones of serotonergic neurons acquire synaptic vesicles as early as F.20 is strongly supported by studies of the distribution in fractions of two markers, SBP and synaptophysin, which are found in synaptic vesicles in adult neu- rons. Synaptophysin is an integral membrane protein of the small synaptic vesicles that are present in all presynaptic nerve endings (Navone et al., 1986; Floor and Feist, 1989; De Camilli and Jahn, 1990). In fact, even when expressed by transfected non-neuronal cells, synaptophysin is sorted into small recycling vesicles (Johnston et al., 1989; Leube et al., 1989). Only neurons or neuroendocrine cells, however, appear to be able to sort synaptophysin-containing vesicles away from other early endosomes into a synaptic vesicle population (Linstedt and Kelly, 1991). SBP is concentrated in synaptosomes, in vesicles liberated from them in vitro (Tamir and Gershon, 1979), and in the secretory vesicles of 5-HT-secreting paraneurons (Barasch et al., 1987; Tamir et al., 1990; Cidon et al., 1991). SBP is also subject to fast axonal transport (Tamir and Gershon, 1979), as are other components of synaptic vesicles (Grafstein, 1977), and SBP is released from stimulated serotonergic neurons by exocytosis (Jonakait et al., 1979). The $\sim 45 \mathrm{kDa}$ form of SBP, moreover, forms a complex with 5 -HT in synaptic vesicles in serotonergic ncrve terminals in vivo (Gershon et al., 1983). SBP is thus a marker for synaptic vesicles derived from serotonergic neurons. The observation, therefore, that synaptophysin is enriched in IGC fractions suggests that synaptic vesicles are present in growth cones. This idea is strengthened by the enrichment of SBP found in the same fractions, which also implies that the subset of growth cones in the IGC fractions that is derived from serotonergic neurons contains synaptic vesicles. These data, taken together with the evidence, derived from studies with reserpine (discussed above), that these vesicles contain the amine carrier, support the conclusion that the growth cones of serotonergic neurons contain synaptic vesicles. The presence of small clear vesicles in electron micrographs of IGC adds further support to this conclusion.

Although some previous studies of the expression of synaptophysin have reported that it develops in parallel with the appearance of mature synapses (Knaus et al., 1986; Devoto and Barnstable, 1989; Taylor et al., 1990), many other studies suggest that it is found in growth cones. Before the development of significant numbers of synapses in the rat cerebellum, for example, synaptophysin-immunoreactive vesicles were observed in growth cones (Leclerc et al., 1989). Similarly, immunoreactivity of synapsin I (which is also associated with synaptic vesicles; De Camilli et al., 1990) was demonstrated to be present in growth cones of the developing mouse cerebellum long before nerve endings and synaptic contacts mature (Mason, 1986). Synapsin I immunoreactivity in cerebellar growth cones correlated with the presence of synaptic vesicles in these structures. The extending axons of developing motor nerves contain immunoreactive synaptic vesicle markers and these are particularly prominent in growth cones (Lupa and Hall, 1989). Restriction of the immunoreactivity of vesicular proteins to nerve terminals has been reported to be a progressive feature of maturation (Mason, 1986; Chun and Shatz, 1988; Lupa and Hall, 1989). The onset of the appearance of the immunoreactivity of another synaptic vesicle protein, $\mathrm{p} 65$, has been reported to precede that of synapsin I and the presumed period of synapse formation in the chick brain (Bixby and Reichardt, 1985). Finally, synaptophysin and synapsin I have each been shown to be distributed in distal axons and growth cones of developing hippocampal neurons in culture (Fletcher et al., 1991).

The possibility that the enrichment of SBP and synaptophysin immunoreactivities in IGC fractions is not due to the presence of synaptic vesicles has not been completely excluded. Con- 
ceivably, these proteins are located in other components of growth cones, which may be precursors of synaptic vesicles. It has previously been suggested that synaptic vesicles may be formed (De Camilli and Jahn, 1990) from smooth membranous structures, which are abundant in growth cones (Cheng and Reese, $1985,1987)$ and preterminal axons of mature neurons (Droz and Rambourg, 1982). Our observation, however, that a reserpine-sensitive amine carrier protein, which can protect 5-HT from catabolism, presumably by catalyzing its uptake into a vesicular compartment, is also present in growth cones by E20, suggests that they must contain structures that are functionally similar to synaptic vesicles. In cultured hypothalamic neurons, furthermore, synaptophysin immunoreactivity in the trans-most cisternae of the Golgi apparatus has been demonstrated to be incorporated into vesicles that look like synaptic vesicles; moreover, synaptophysin immunoreactivity is transported from cell body to axon terminals in the membrane of recognizable vesicles (Tixier-Vidal et al., 1988). Only limited synaptophysin immunoreactivity was observed to be associated with the smooth endoplasmic reticulum (Tixier-Vidal et al., 1988).

Our observation that IGC fractions contain general and 5-HTspecific synaptic vesicle markers as well as the plasma membrane 5-HT transporter before the onset of cortical synaptogenesis suggests that the growth cones of serotonergic neurons have acquired many, if not all, of the components of the neurotransmitter machinery before mature synapses are formed. The transmitter apparatus of growth cones, therefore, may serve a developmental function. The acquisition of synaptic vesicles by E20 is consistent with the possibility that growth cones utilize the neurotransmitter during development. Studies of IGC fractions obtained from early rat brain suggest that growth cones are unable to secrete 5-HT before they acquire vesicles of the synaptic type (Lockerbie et al., 1991). The present observation, however, that synaptic vesicles appear in serotonergic neurons before synaptogenesis, and evidence that 5-HT can be secreted by growing axons (Reisert et al., 1989; Ugrumov et al., 1989; Azmitia et al., 1990) are consistent with the idea that 5-HT plays a role in development (Lauder and Krebs, 1978; Lauder et al., 1988; Hamon et al., 1989; Lauder 1991). 5-HT, for example, has been shown to be a stop signal for growth cones in developing snail ganglia, halting neurite elongation and synapse formation (Haydon et al., 1987; McCobb et al., 1988). Similarly, cultured rat cortical neurons respond to 5 -HT by decreasing neurite elongation and neurite branching (Sikich et al., 1990). Certainly, a neurotransmitter can be released from growth cones. Secretion of ACh from the growth cones of cholinergic motor neurons occurs spontaneously and in response to electrical stimulation (Hume et al., 1983; Young and Poo, 1983).

In summary, it can be concluded that the growth cones of serotonergic neurons display characteristics of mature synaptic terminals. These characteristics include the plasma membrane 5-HT transporter and an internal 5-HT storage compartment that has properties in common with synaptic vesicles. These observations suggest that synaptogenesis involving serotonergic neurons may involve the reorganization of preexisting components that are already present in growth cones. This "prefabrication" of the essential elements of the presynaptic components of synapses may cnablc physiological activity to be rapidly established when serotonergic synaptic contacts are formed. Contact of pre- and postsynaptic components of a synapse may thus rapidly be followed by neurotransmission. Such early establishment of activity could be important in determining the ability of developing synapses to survive and persist in a competitive environment (Frank, 1987; Shatz, 1990). The presence of neurotransmitter mechanisms in growth cones is compatible with suggestions that have been made in the literature that $5-\mathrm{HT}$ plays a role in neural development.

\section{References}

Angelides KJ (1980) Transport of catecholamines by native and reconstituted rat heart synaptic vesicles. J Neurochem 45:949-962.

Azmitia EC, Frankfurt M, Davila M, Whitaker-Azmitia PM, Zhou FC (1990) Plasticity of fetal and adult CNS serotonergic neurons: role of growth-regulatory factors. Ann NY Acad Sci 600:343-365.

Bäckström IT, Marcusson JO (1987) 5-Hydroxytryptamine-sensitive ${ }^{3} \mathrm{H}$-imipramine binding of protein nature in the human brain. $\mathrm{I}$. Characteristics. Brain Res 425:128-136.

Barasch JM, Tamir H, Nunez EA, Gershon MD (1987) Serotoninstoring secretory granules from thyroid parafollicular cells. J Neurosci 7:4017-4033.

Bixby JL, Reichardt LF (1985) The expression and localization of synaptic vesicles antigens at the neuromuscular junction in vitro. $\mathrm{J}$ Neurosci 5:3070-3080.

Blakely RD, Berson HE, Fremeau RT, Caron MG, Peek MM, Prince HK, Bradley CC (1991) Cloning and expression of a functional serotonin transporter from rat brain. Nature 354:66-70.

Bray D, Hollenbeck PJ (1988) Growth cone motility and guidance. Annu Rev Cell Biol 4:43-61.

Bretz R, Staubli W (1977) Detergent influence on rat-liver galactosyltransferase activity towards different acceptors. Eur J Biochem 77: 181-192.

Briley M (1985) Imipramine binding: its relationship with serotonin uptake and depression. In: Neuropharmacology of serotonin (Green AR, ed), pp 50-78. New York: Oxford UP.

Carlsson A (1965) Drugs that block the storage of 5-hydroxytryptamine and related amines. Handbk Exp Pharmacol 19:529-592.

Cheng TPO, Reese TS (1985) Polarized compartmentation of organelles in growth cones from developing optic tectum. J Cell Biol 101: 1473-1480.

Cheng TPO, Reese TS (1987) Recycling of plasmalemma in chick tectal growth cones. J Neurosci 7:1752-1759.

Chun JJM, Shatz CJ (1988) Redistribution of synaptic vesicle antigens is correlated with the disappearance of a transient synaptic zone in the developing cerebral cortex. Neuron 1:297-310.

Cidon S, Tamir H, Nunez EA, Gershon MD (1991) ATP-dependent uptake of 5-hydroxytryptamine by secretory granules isolated from thyroid parafollicular cells. J Cell Biol 266:4392-4400.

Cohen RS, Blomberg F, Berzins K, Siekevitz P (1977) The structure of postsynaptic densities isolated from dog cerebral cortex. J Cell Biol 74:181-203.

De Camilli P, Jahn R (1990) Pathways to regulate exocytosis in neurons. Annu Rev Physiol 52:625-645.

De Camilli P, Benfenati F, Valtorta F, Greengard P (1990) The synapsins. Annu Rev Cell Biol 6:433-460.

De Souza EB, Kuyatt BL (1987) Autoradiographic localization of ${ }^{3} \mathrm{H}-$ paroxetine-labeled serotonin uptake sites in rat brain. Synapse 1:488496.

Devoto SH (1990) Neural growth cone migration. Experientia 46: 916-922.

Devoto S, Barnstable CJ (1989) Expression of the growth cone specific epitope CDA1 and the synaptic vesicle protein SVP38 in the developing mammalian cerebral cortex. J Comp Neurol 290:154-168.

Droz B, Rambourg A (1982) Axonal smooth endoplasmic reticulum and fast orthograde transport of membrane constituents. In: Axonal transport (Weiss D, ed), pp 384-389. Berlin: Springer.

Elias H, Henning A, Schwartz DE (1971) Stereology: application to biomedical research. Physiol Rev 51:158-200.

Erde SM, Sherman D, Gershon MD (1985) Morphology and serotonergic innervation of physiologically identified cells of the guinea pig's myenteric plexus. J Neurosci 5:617-633.

Fletcher TL, Cameron P, De Camilli P, Banker G (1991) The distribution of synapsin I and synaptophysin in hippocampal neurons developing in culture. $J$ Neurosci 11:1617-1626.

Floor E, Feist BE (1989) Most synaptic vesicles isolated from rat brain carry three membrane proteins, SV2, synaptophysin, and p65. J Neurochem 52:1433-1437. 
Frank E (1987) The influence of neuronal activity on patterning of neural connections. Trends Neurosci 10:188-190.

Fujimiya M, Hosoda S, Kitahama K, Kimura H, Maeda T (1986) Early development of serotonin neurons in the rat brain as studied by immunocytochemistry combined with tryptophan administration. Brain Dev 8:336-342.

Gershon MD, Ross LL (1966) Radioisotopic studies of the binding, exchange, and distribution of 5-hydroxytryptamine synthesized from its radioactive precursor. J Physiol (Lond) 186:451-476.

Gershon MD, Tamir H (1984) Serotonectin and the family of proteins that bind serotonin. Biochem Pharmacol 33:3115-3118.

Gershon MD, Tamir H (1985) Peripheral sources of serotonin and serotonin binding proteins. In: Serotonin and the cardiovascular system, pp 15-26. New York: Raven.

Gershon MD, Liu KP, Karpiak SE, Tamir H (1983) Storage of serotonin in vivo as a complex with serotonin binding protein in central and peripheral serotonergic neurons. J Neurosci 3:1901-1911.

Gershon MD, Sherman DL, Pintar JE (1990) Type-specific localization of monoamine oxidase in the enteric nervous system: relationship to 5-hydroxytryptamine, neuropeptides, and sympathetic nerves. J Comp Neurol 301:191-213.

Giachetti A, Hollenbeck RA, Shore PA (1974) Localization and binding of reserpine in the membrane of adrenomedullary amine storage granules. Naunyn -Schmiedebergs Arch Pharmacol 238:263-275.

Gordon-Weeks PR, Lockerbie RO, Pearce BR (1984) Uptake and release of ${ }^{3} \mathrm{H}-\mathrm{GABA}$ by growth cones isolated from neonatal rat brain. Neurosci Lett 52:205-210.

Goslin K, Schreyer DJ, Skene JHP, Banker G (1988) Development of ncuronal polarity: GAP-43 distinguishes axonal from dendritic growth cones. Nature 336:672-674.

Goslin K, Schreyer DJ, Skene JHP, Banker G (1990) Changes in the distribution of GAP-43 during the development of neuronal polarity. J Neurosci 10:588-602.

Gotow T, Sotelo C (1987) Postnatal development of the inferior olivary complex: VI. Synaptogenesis of GABAergic afferents, analyzed by glutamic acid decarboxylase immunocytochemistry. J Comp Neurol 263:526-552

Grabowsky KL, McCabe RT, Wamsley JK (1983) Localization of ${ }^{3} \mathrm{H}-$ imipramine binding sites in rat brain by light microscopic autoradiography. Life Sci 32:2355-2361.

Grafstein B (1977) Axonal transport: the intracellular traffic of the neuron. In: Handbook of physiology, The nervous system. Bethesda MD: Amcrican Physiological Socicty.

Graham D, Esnaud H, Habert E, Langer SZ (1989) A common binding site for tricyclic and nontricyclic 5-hydroxytryptamine uptake inhibitors at the substrate recognition site of the neuronal sodium-dependent 5-hydroxytryptamine transporter. Biochem Pharmacol 38:38193826 .

Greenawalt JW (1972) Localization of monoamine oxidase in rat liver Mitochondria. In: Advances in biochemical psychopharmacology, Vol 5, monoamine oxidases-new vistas (Costa E, Sandler M, eds), pp 207-226. New York: Raven.

Habert E, Graham D, Tahraoui L, Claustre Y (1985) Characterization of ${ }^{3} \mathrm{H}$-paroxetine binding to rat cortical membranes. Eur J Pharmacol 118:107-114.

Hamon M, Bourgoin S (1982) Characteristics of 5-HT metabolism and function in the developing brain. In: Biology of serotonergic transmission (Osborn NN, ed), pp 197-220. Chichester: Wiley.

Hamon M, Bourgoin S, Chanez C, De Vitry F (1989) Do serotonin and other neurotransmitters exert a trophic influence on the immature brain? In: Nestle nutrition workshop series: developmental neurobiology (Evrard P, Minkowski A, eds), pp 171-183. New York: Nestec, Vevey/Raven.

Haydon PG, McCobb DP, Kater SB (1987) The regulation of neurite outgrowth, growth cone motility, and electrical synaptogenesis by serotonin. J Neurobiol 18:197-215.

Herregodts P, Velkenier B, Ebinger G, Michotte Y, Vanhaelst L, HooghePeters E (1990) Development of monoaminergic neurotransmitters in fetal and postnatal rat brain: analysis by HPLC with electrochemical detection. J Neurochem 55:774-779.

Hoffman B, Mezey E, Brownstein M (1991) Cloning of a scrotonin transporter affected by antidepressants. Science 254:579-580.

Hrdina PD (1988) Inhibition of sodium-dependent ${ }^{3} \mathrm{H}$-imipramine binding in rat brain by serotonin and serotonin uptake inhibitors. Eur J Pharmacol 148:279-282.
Hrdina P, Foy B, Hepner A, Summers RJ (1990) Antidepressant binding sites in brain: autoradiographic comparison of ${ }^{3} \mathrm{H}$-paroxetine and ${ }^{3} \mathrm{H}$-imipramine localization and relationship to serotonin transporter. J Pharmacol Exp Ther 252:410-418.

Hume RI, Role LW, Fischbach GD (1983) Acetylcholine release from growth cones detected with patches of acetylcholine receptor-rich membranes. Nature 305:632-634.

Jahn R, Schiebler W, Greengard P (1984) A quantitative dot-immunobinding assay for proteins using nitrocellulose membrane filters. Proc Natl Acad Sci USA 81:1684-1687.

Jahn R, Schiebler W, Ouimet C, Greengard P (1985) A 38,000-dalton membrane protein (p38) present in synaptic vesicles. Proc Natl $\Lambda$ cad Sci USA 82:4137-4141.

Johnston PA, Jahn R, Sudhof TC (1989) Transmembrane topography and evolutionary conservation of synaptophysin. J Biol Chem 264 : $1268-1273$.

Jonakait GM, Tamir H, Gintzler AR, Gershon MD (1979) Release of $\left[{ }^{3} \mathrm{H}\right]$ serotonin and its binding protein from enteric neurons. Brain Res 174:55-69.

Kirchgessner AL, Gershon MD, Liu KP, Tamir H (1988) Co-storage of serotonin binding protein with serotonin in the rat CNS. J Neurosci 8:3879-3890.

Knaus P, Betz H, Rehm H (1986) Expression of synaptophysin during postnatal development of the mouse brain. J Neurochem 47:13021303.

Laemmli UK (1970) Cleavage of structural proteins during the assembly of the head of bacteriophage T4. Nature 227:680-685.

Landis SC (1983) Neuronal growth cones. Annu Rev Physiol 45:567580.

Lauder JM (1991) Ontogeny of serotonergic system in the rat: serotonin as a developmental signal. Ann NY Acad Sci 600:297-314.

Lauder JM, Bloom FE (1974) Ontogeny of monoamine neurons in the locus coeruleus, raphe nuclei and substantia nigra of the rat. I. Cell differentiation. J Comp Neurol 155:469-482.

Lauder JM, Bloom FE (1975) Ontogeny of monoamine neurons in the locus coeruleus, raphe nuclei and substantia nigra of the rat. II. Synaptogenesis. J Comp Neurol 163:251-264.

Lauder JM, Krebs H (1978) Serotonin as a differentiation signal in early neurogenesis. Dev Neurosci 1:15-30.

Lauder JM, Wallace JA, Krebs H, Petrusz P, McCarthy K (1982) In vivo and in vitro development of serotonergic neurons. Brain Res Bull 9:605-625.

Lauder JM, Tamir H, Sadler TW (1988) Serotonin and morphogenesis. I. Sites of serotonin uptake-binding protein immunoreactivity in the midgestation mouse embryo. Development 102:709-720.

Leclerc N, Beesley PW, Brown I, Colonnier M, Gurd JW, Paladino T, Hawkes R (1989) Synaptophysin expression during synaptogenesis in the rat cerebellar cortex. J Comp Neurol 280:197-212.

Leube RE, Wiedenmann B, Franke WW (1989) Topogenesis and sorting of synaptophysin: synthesis of a synaptic vesicle protein from a gene transfected into non-neuroendocrine cells. Cell 59:433-446.

Levitt P, Maxwell GD, Pintar JE (1985) Specific cellular expression of monoamine oxidase $B$ during early stages of quail embryogenesis. Dev Biol 1 10:346-361.

Lidov HGW, Molliver ME (1982a) An immunohistochemical study of serotonin neuron development in the rat: ascending pathways and terminal fields. Brain Rcs Bull 8:389-430.

Lidov HGW, Molliver ME (1982b) Immunohistochemical study of the development of serotonergic neurons in the rat CNS. Brain Res Bull 9:559-604

Linstedt AD, Kelly RB (1991) Synaptophysin is sorted from endocytotic markers in neuroendocrine PC12 cells but not transfected fibroblasts. Neuron 7:309-317.

Lipton SA, Kater SB (1989) Neurotransmitter regulation of neuronal outgrowth, plasticity and survival. Trends Neurosci 12:265-270.

Liu KP, Tamir H, Hsiung S, Adlersberg M (1987) Prenatal development of serotonin binding protein in relation to other transmitterrelated characteristics of central serotonergic neurons. Dev Brain Res 32:31-41.

Liu KP, Yu P-Y, Hsiung SH, Kirchgessner AL, Gershon MD, Tamir II (1990) Preparation and characterization of monoclonal antibodies to serotonin binding protein. J Neurochem 55:1013-1021.

Liu Y, Peter D, Roghani A, Schuldiner S, Privé GG, Eisenberg D, Brecha $\mathrm{N}$, Edwards RH (1992) A cDNA that suppresses $\mathrm{MPP}^{+}$toxicity encodes a vesicular amine transporter. Cell 70:539-551. 
Lockerbie RO (1987) The neuronal growth cone: a review of its locomotory, navigational and target recognition capabilities. Neuroscience 20:719-729.

Lockerbie RO (1990) Biochemical pharmacology of isolated neuronal growth cones: implications for synaptogenesis. Brain Res Rev 15: 145-165.

Lockerbie RO, Gordon-Weeks PR, Pearce BR (1985) Growth cones isolated from developing rat forebrain: uptake and release of GABA and noradrenaline. Dev Brain Res 21:265-275.

Lockerbie RO, Miller VE, Pfenninger KH (1991) Regulated plasmalemmal expansion in nerve growth cones. J Cell Biol 112:1215-1227.

Loizou LA (1972) The postnatal ontogeny of monoamine-containing neurons in the central nervous system of the albino rat. Brain Res 40:395-418.

Loizou LA, Salt P (1970) Regional changes in monoamines of the rat brain during postnatal development. Brain Res 20:467-470.

Lowry OH, Rosenbrough NJ, Fair AL, Randall RJ (1951) Protein measurement with the folin phenol reagent. J Biol Chem 193:265275.

Lupa MT, Hall ZW (1989) Progressive restriction of synaptic vesicle protein to the nerve terminal during development of the neuromuscular junction. J Neurosci 9:3937-3945.

Marcusson J, Fowler CJ, Hall H, Ross SB, Winblad B (1985) "Specific" binding of ${ }^{3} \mathrm{H}$-imipramine to protease-sensitive and protease-resistant sites. J Neurochem 44:705-711.

Marcusson JO, Bäckström IT, Ross SB (1986) Singlc-site model of the neuronal 5-hydroxytryptamine uptake and imipramine-binding site. Mol Pharmacol 30:121-128.

Marcusson JO, Bergström M, Eriksson K, Ross SB (1988) Characterization of ${ }^{3} \mathrm{H}$-paroxetine binding in rat brain. $\mathrm{J}$ Neurochem 50 : $1783-1790$

Marcusson JO, Andersson A, Bäckström I (1989) Drug inhibition indicates a single-site model of the 5-HT uptake site/antidepressant binding site in the rat and human brain. Psychopharmacology 99:1721 .

Maron R, Kanner BI, Schuldiner S (1979) The role of a transmembrane $\mathrm{pH}$ gradient in 5-hydroxy tryptamine uptake by synaptic vesicles from rat brain. FEBS Lett 98:237-240.

Mason CA (1986) Axon development in mouse cerebellum: embryonic axon forms and expression of synapsin I. Ncurosciencc 19:13191333.

Mattson MP (1988) Neurotransmitters in the regulation of neuronal cytoarchitecture. Brain Res Rev 13:179-212.

McCobb DP, Haydon PG, Kater SB (1988) Dopamine and serotonin inhibition of neurite elongation of different identified neurons. J Neurosci Res 19:19-26.

McLaughlin BJ, Wood JG, Saito K, Roberts E, Wu J-Y (1975) The fine structural localization of glutamate decarboxylase in developing axonal processes and pre-synaptic terminals of rodent cerebellum. Brain Res 85:355-371.

Meiri KF, Pfenninger KH, Willard MB (1986) Growth associated protein, GAP-43, a peptide that is induced when neurons extend axons, is a component of growth cones and corresponds to pp-46, a major polypeptide of a subcellular fraction enriched in growth concs. Proc Natl Acad Sci USA 83:3537-3541.

Navone F, Jahn R, Di Gioia G, Stukenbrok H, Greengard P, De Camilli $P$ (1986) Protein p38: an integral membrane protein specific for small vesicles of neurons and neuroendocrine cells. J Cell Biol 103: 2511-2527.

Olson L, Seiger A (1972) Early prenatal ontogeny of central monoamine neurons in the rat: fluorescence histochemical observation. $Z$ Anat Entwicklungsgesch 137:301-316.

Palacios JM, NiehoffDL, Kuhar MJ (1981) Receptor autoradiography with tritium sensitive film: potential for computerized densitometry. Neurosci Lett 25:101-105.

Pfenninger KH, Ellis L, Johnson MP, Friedman LB, Somlo S (1983) Nerve growth cones isolated from fetal rat brain. I. Subcellular fractionation and characterization. Cell 35:573-584.

Raisman R, Briley M, Langer SZ (1979) High affinity ${ }^{3} \mathrm{H}$-imipramine binding in rat cerebral cortex. Eur J Pharmacol 61:373.

Rehavi M, Skolnick P, Paul SM (1983) Subcellular distribution of high affinity ${ }^{3} \mathrm{H}$-imipramine binding and ${ }^{3} \mathrm{H}$-serotonin uptake in rat brain. Eur J Pharmacol 87:335-339.

Reisert I, Han V, Hartwig S, Ahnert-Hilger G, Pilgrim C (1989) Rapid maturation of synaptic functions of prenatal serotoninergic neurons in short-term cultures: absence of sex differences and hormone effects. Neuroscience 32:133-139.

Ross SB (1982) The characteristics of serotonergic uptake systems. In: Biology of serotonergic transmission (Osborn NN, ed), pp 159195. Chichester: Wiley.

Salpeter MM, Bachmann L, Salpeter EE (1969) Resolution in electron microscope radioautography. J Cell Biol 41:1-20.

Schmidt MJ, Sander-Bush E (1971) Tryptophan hydroxylase activity in developing rat brain. $\mathrm{J}$ Neurochem 18:2549-2551.

Seiger A, Olson L (1973) Late prenatal ontogeny of central monoamine neurons in the rat: fluorescence histochemical observations. Z Anat Entwicklungsgesch 140:281-318.

Sette M, Raisman R, Briley M, Langer SZ (1981) Localization of tricyclic antidepressant binding sites on serotonin nerve terminals. J Neurochem 37:40-42.

Severson JA, Woodward JJ, Wilcox RE (1986) Subdivision of mouse brain ${ }^{3} \mathrm{H}$-imipramine binding based on ion dependence and serotonin sensitivity. J Neurochem 46:1743-1754.

Shatz CL (1990) Impulse activity and the patterning of connections during CNS development. Neuron 5:745-756

Shore PA, Giachetti A (1978) Reserpine: basic and clinical pharmacology. In: Handbook of psychopharmacology (Iversen LL, Iversen SD, Snyder SH, eds), p 197. New York: Plenum.

Sikich L, Hickok JM, Todd RD (1990) 5- $\mathrm{HT}_{1 \mathrm{~A}}$ receptors control neurite branching during development. Dev Brain Res 56:269-274.

Skene JHP, Jacubsun RD, Snipes GJ, McGuire CB, Norden JJ, Freeman JA (1986) A protein induced during nerve growth (GAP-43) is a major component of growth cone membranes. Science 233:783-786.

Sudhof TC, Jahn R (1991) Proteins of synaptic vesicles involved in exocytosis and membrane recycling. Neuron 6:665-677

Sun Y-A, Poo M-M (1987) Evoked release of acetylcholine from the growing embryonic neurons. Proc Natl Acad Sci USA 84:2540-2544.

Tamir H, Gershon MD (1979) Storage of serotonin and serotonin binding protein in synaptic vesicles. J Neurochem 33:35-44.

Tamir H, Liu KP, Hsiung SC, Adlersberg M, Nunez EA, Gershon MD (1990) Multiple signal transduction mechanisms leading to the secretion of 5-hydroxytryptamine by MTC cells, a neuroectodermally derived cell line. J Neurosci 10:3743-3753.

Taylor J, Gordon-Weeks PR (1989) Developmental changes in the calcium dependency of $\gamma$-aminobutyric acid release from isolated growth cones: correlation with growth cone morphology. J Neurochem 53:834-843.

Taylor J, Docherty M, Gordon-Weeks PK (1990) GABAergic growth cones: release of endogenous $\gamma$-aminobutyric acid precedes the expression of synaptic vesicles antigens. J Neurochem 54:1689-1699.

Tissari AH (1975) Pharmacological and ultrastructural maturation of serotonergic synapses during maturation. Med Biol 53:1-14.

Tixier-Vidal A, Faivre-Bauman A, Picart R, Wiedenmann B (1988) Immunoelectron microscopic localization of synaptophysin in a Golgi subcompartment of developing hypothalamic neurons. Neuroscience 26:847-861.

Towbin H, Saehelin T, Gordon J (1979) Electrophoretic transfer of proteins from polyacrylamide gels to nitrocellulose sheets: procedure and some applications. Proc Natl Acad Sci USA 76:4350-4354.

Ugrumov MV, Proshlyakova EV, Sapronova A (1989) Development of the hypothalamic 5-hydroxytryptamine system during ontogenesis in rats: uptake and release of 5-hydroxytryptamine in vitro. Neuroscience $32: 127-131$.

Wallace JA, Lauder JM (1983) Development of the serotonergic system in the rat embryo: an immunocytochemical study. Brain Res Bull 10:459-479.

Westenbroek RE, Westrum LE, Hendrickson AE, Wu J-Y (1988) UItrastructural localization of immunoreactivity in the developing piriform cortex. J Comp Neurol 274:319-333.

Wiedenmann B, Franke WW (1985) Identification and localization of synaptophysin, an integral membrane glycoprotein of $M_{r} 38,000$ characteristic of presynaptic vesicles. Cell 41:1017-1028.

Williams A (1969) The assessment of electron microscopic autoradiographs. Adv Opt Electron Microsc 3:219-272.

Yamamoto M, Steinbusch SWM, Jessell TM (1981) Differentiated properties of identified serotonergic neurons in dissociated cultures of embryonic rat brain stem. J Cell Biol 91:142-152.

Young SH, Poo M-M (1983) Spontaneous release of transmitter from growth cones of embryonic neurons. Nature 305:634-637. 